\title{
Exploiting Nanoparticles to Improve the Properties of Bitumens and Asphalts: At What Extent Is It Really Worth It?
}

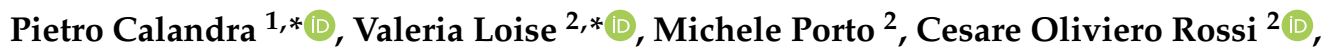 \\ Domenico Lombardo $^{3}$ (D) and Paolino Caputo ${ }^{2}$ (D) \\ 1 CNR-ISMN, National Research Council-Institute for the Study of Nanostructured Materials, \\ Via Salaria km 29.300, 00015 Monterotondo Stazione (RM), Italy \\ 2 Department of Chemistry and Chemical Technologies, University of Calabria, \\ 87036 Arcavacata di Rende (CS), Italy; michele.porto@unical.it (M.P.); cesare.oliviero@unical.it (C.O.R.); \\ paolino.caputo@unical.it (P.C.) \\ 3 CNR-IPCF, National Research Council-Institute for the Physico-Chemical Processes-Viale Ferdinando \\ Stagno d'Acontres, 98158 Messina, Italy; lombardo@ipcf.cnr.it \\ * Correspondence: pietro.calandra@cnr.it (P.C.); valeria.loise@unical.it (V.L.)
}

Received: 18 June 2020; Accepted: 25 July 2020; Published: 29 July 2020

\begin{abstract}
Asphalt concretes are materials used worldwide. It is well-known that in such materials the minor component, the bitumen, plays the most important role since it binds the high fraction $(>95 \%)$ of inorganic macrometer-sized particles ensuring a coherent material fit for uses in road pavement. Additives can be used to increase the overall rheological properties, with high benefits in terms of resistance to mechanical stress and to ageing. Among these, nanoparticles have recently been considered as very effective additives in increasing the overall performance, increasing the viscosity, the rutting parameter and the recovery from deformation. However, they are expensive, so a delicate equilibrium between costs and benefits must be found for large-scale uses. In this framework, we furnish our critical analysis of the state-of-the art technologies used for improving the bitumen performances by means of nanoparticles with an eye to eventual added-values (like anti-oxidant effect, antistripping properties, or UV radiation screening which avoids radiation-induced ageing ... ). We will critically consider the costs involved in their use and we will give our opinion about vanguard techniques which can be fit for the analysis of nanoparticles-containing bitumens and asphalts. Interesting perspectives will be also given for future research and applications.
\end{abstract}

Keywords: nanoparticles; bitumen; asphalts; surface functionalization

\section{Aim of the Work}

This work is far from being a review of the state-of-the art technologies, methods and materials used for using nanoparticles-containing bitumens and asphalts. For this, specialised textbooks, good reviews, and interesting research articles are present. They can furnish all the necessary information. This work is, instead, a critical presentation of this field, introducing the reader to the properties of nanoparticles and their use to improve the properties of bitumens and asphalt concretes. For this purpose, the various kinds of nanoparticles (nanosilica, nanoceramics, nanoclays, and even organic nanoparticles or inorganic nanoparticles surface-functionalised) used in this field will be rationally classified and presented. The added-value properties they confer to bituminous materials will be critically discussed, highlighting at the same time both positive and negative aspects, costs included. The purpose is to furnish useful and critic comparisons, suggestions and perspectives. This work is therefore a thought commentary on all the aspects involved in this topic, from the physical origin of 
the emergence of novel properties, to the principles to be followed to choose the most appropriate technique of investigation, according to the complex nature of the material involved and according to the specific chemical aspect needing investigation. The aim of the work is then to provide a panoramic view of the state-of-the art, making useful criticisms and giving comments and suggestions, to make researchers conscious of several hidden aspects that can be hardly found in standard research articles (for instance how to analyse IR spectra, how to improve the excitonic absorption to make bitumens resistant to UV radiation, how to investigate the distribution of nanoparticles in the bulk state rather than in the surface as usually done by standard microscopies, the eternal costs/benefits struggle, need of interdisciplinary works etc.). To do so, the work will follow this logical scheme: we first show (Sections 2 and 3) the peculiar properties of bitumens and how they can be improved by the use of nanoparticles and why; then we present the problems to be faced: the issue of nanoparticle stabilization and the cost involved. To show how to face these problems, we will present the possible solutions to obtain a reasonable cost/benefit equilibrium, in order, from the cheapest solution (use of inorganic nanoparticles), gradually moving to surface-functionalized nanoparticles up to the use of organic nanostructures (Sections 4-6). Then, we will comment the added values conferred by the nanoparticles (Section 7) and the experimental methods for a proper characterization (Section 8), to finally conclude with future perspectives as we see them (Section 9).

It is our conviction that literature is quite rich in experimental works related to the use of nanoparticles in bitumens, but it is still relatively poor in works critically commenting the state-of-the art and offering different points of view especially on the basis of the fascinating fields of molecular physics and the physics of complex systems. We hope that this contribution could finally tickle researchers' curiosity and stimulate their imagination in the piloted design of material for road pavements with ever-increasing performances.

\section{An Introduction to the Problematics}

\subsection{Bitumen and Asphalt Generalities}

Bitumen is an involatile, adhesive, waterproofing, highly viscous viscoelastic fluid derived from the crude oil topping distillation process or present in natural sources [1]. Its composition and physicochemical properties depend on the crude oil sources undergoing the distillation process [2,3]. However, the molecules present in a bitumen are not uniquely defined so the bitumen is classified according to the relative amounts of four classes of molecules (Saturates, Aromatics, Resins and Asphaltenes), never by the definition of the millions of constituents individually [4].

A typical composition is reported in the top panel of Figure 1. However, the exact relative fractions of any specific bitumen can be determined by the S.A.R.A. method [5], usually following the ASTM D4124-09(2018) procedure.

Bitumen viscoelastic properties allow its use as binder for the inorganic particles used in road paving. In this use, it is heated so that its viscosity decreases sufficiently [6] to allow it to be properly mixed with the aggregates; after cooling down to ambient temperature, the bitumen will act as a viscous binder of the aggregates.

Bitumen has a very complex structure consisting of polar asphaltene stacks of aggregates stabilized by resins and dispersed in apolar components (saturates and aromatics). The similarity with micellar systems gives this picture the name of "micellar model", but the structures turn out to be more complex since asphaltene clusters are organized in complex way at various hierarchical levels of different length-scales [7].

The complexity of this system is even higher if we consider that both the composition and (therefore) the structure changes with time, since ageing takes place with various mechanisms leading to brittleness with time $[8,9]$. 


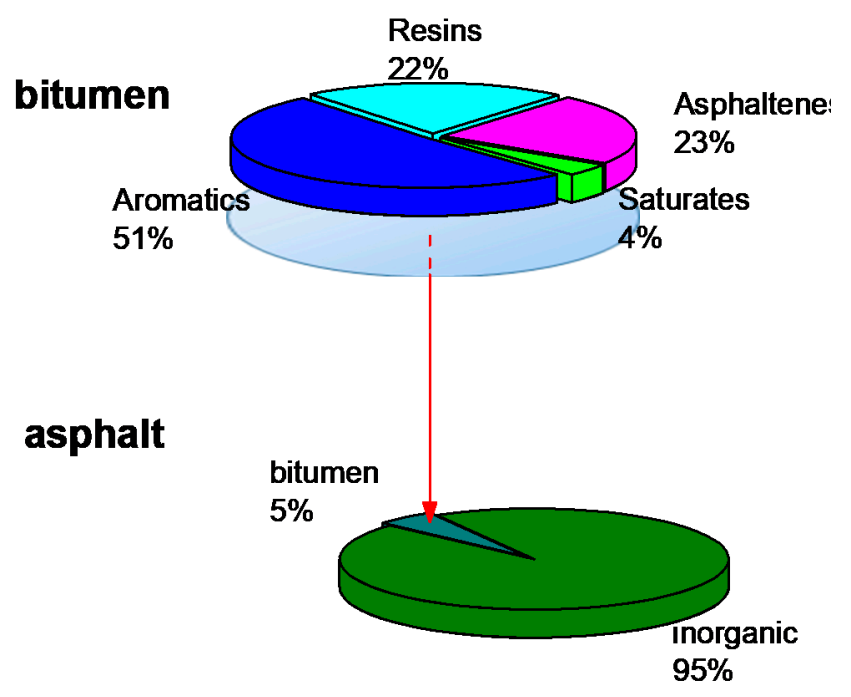

Figure 1. Typical compositions of asphalts and bitumens.

\subsection{Our Opinion on The Role of Resins and Amphiphiles}

The maltene glass transition temperature is certainly an important factor governing the rheological properties [6], but effective asphaltene content and their aggregation state is practically the most important factor dictating properties of the bitumen and resulting asphalt [10].

For this reason, we want to emphasize the role of resins. To do so we can present chemical reasoning applying to bitumens what is known about colloidal systems: the stabilization of the polar domains is of pivotal importance for determining both the structure and the properties of the overall aggregates.

It is therefore clear that resins are the stabilizing agents that actually hold up the overall structure of the system. This peculiar characteristic is given by their amphiphilic properties, i.e., the molecules have both polar and apolar parts within their molecular architecture. So, at their polar end they can bind the polar clusters of asphaltenes, and at the apolar one, they can bind the maltene, acting as a bridge between the polar and apolar domains which, in absence of such molecules, would be unstable towards segregation/separation/ sedimentation. Without going deeper into details, it is important to point out that their role in the overall self-assembly and dynamics is complex. Besides simple polar and apolar interactions, further specific interactions between amphiphiles themselves can in principle take place.

It has been recently highlighted that the mutual interactions between amphiphiles lead to peculiar self-assembly processes [11,12] sometimes with extended molecular networks, dictating the final overall aggregation pattern [13] and the (usually slowed-down) dynamics [14,15]. In any case, the bottom-up self-assembly of organic-based complex materials is sometimes a very complicated issue [16].

Given the extreme sensitivity of the aggregation pattern to the presence of other amphiphiles, our opinion is that amphiphiles can be considered as one of the most promising and effective classes of substances which can be used for improving the properties of bitumens and asphalts. It is not a case if the most effective and important additives are amphiphilic substances: since resins influence the asphaltene dispersion within the matrix avoiding their aggregation, they promote structural stability hindering the deterioration of the rheological performances [17].

In the context of nanoparticle-containing bitmens and asphalts, the role of resins is even more important, since they must stabilize also the nanoparticles in the apolar maltenic matrix typical of the bitumens.

Amphiphilic compounds have proven in fact to be effective in stabilizing organic-based materials $[18,19]$, inorganic complexes [20,21] and above all inorganic nanoparticles dispersed in the apolar phase [22-24], even under drastic conditions $[25,26]$. Since aggregation is usually a 
thermodynamically favored process, the effect of resins is therefore also important in contrasting ageing effects, thus increasing the service life of the asphalt [27].

\subsection{From Macro Aggregates to Nanoparticles: Size Matters}

A recent definition of nanomaterial concisely given by the European Commission is: "A natural, incidental or manufactured material containing particles, in an unbounded state or as an aggregate or as an agglomerate and where, for $50 \%$ or more of the particles in the size distribution, one or more external dimension is in the size range 1-100 $\mathrm{nm}^{\prime \prime}$ [28].

It has been understood that nanometer-sized particles have unique properties which cannot be found in their relative bulk counterparts. Their use in asphalt production is then becoming more and more appealing: nanoparticles can give increased pavement load and decrease its cracks due to fatigue during the operational life, they boost asphalt concrete pavement long-term performance, they give better resistance to traffic and environmental loads or mitigate the incompatibility between some natural aggregates and the bitumen binder, enabling more sustainable and durable pavement solutions [29]. The origin of this interest can be traced back to the enhanced surface to volume ratio [30]. In Figure 2 it is shown the fraction of surface atoms with respect to the total amount of atoms, making part of a model cubic sample made of atoms arranged in a primitive cubic lattice of lattice spacing $\mathrm{L}_{0}$.

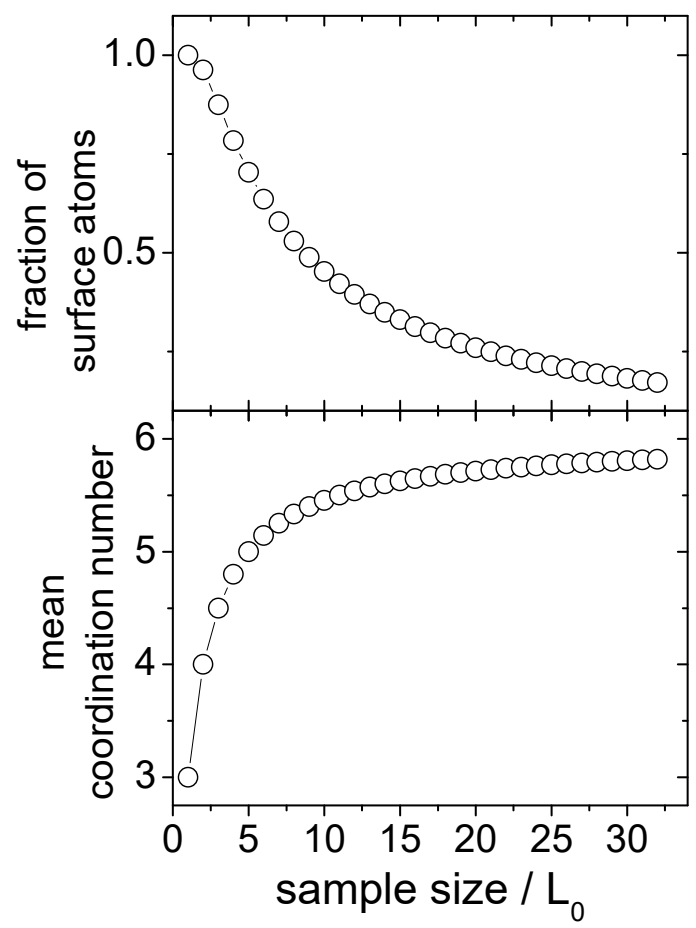

Figure 2. Fraction of surface atoms and mean coordination number in a primitive cubic sample $\left(\mathrm{L}_{0}\right.$ is the atom bond distance, see text for comments).

It can be seen that, with decreasing size, the fraction of surface atoms increases as well as the fraction of low-coordination number atoms (atoms at the edges and at corners). Such atoms have dangling bonds which need to be saturated by bonds with other chemical species and therefore they have peculiar properties and a certain reactivity.

The use of nanosized particles has given rise to a modern technological field: nanotechnology. Many different aspects are included [31]: Nano- and quantum electronics, nanostructured materials, scanning probe microscopy, molecular materials for electronics, molecular technology, computer modelling, cluster and mesoscopic science and technology and supramolecular chemistry, which have all become part of nanotechnology since the late nineties, are to be taken into account. Finally, this new field is nowadays involved in construction and road pavement materials [32-34]. 
Figure 3, inspired from a work by Sobolev and Ferrada-Gutiérrez [35], shows how the use of nanoparticles with sizes down to the nanometer range can be used in various bitumen and asphalt technologies.

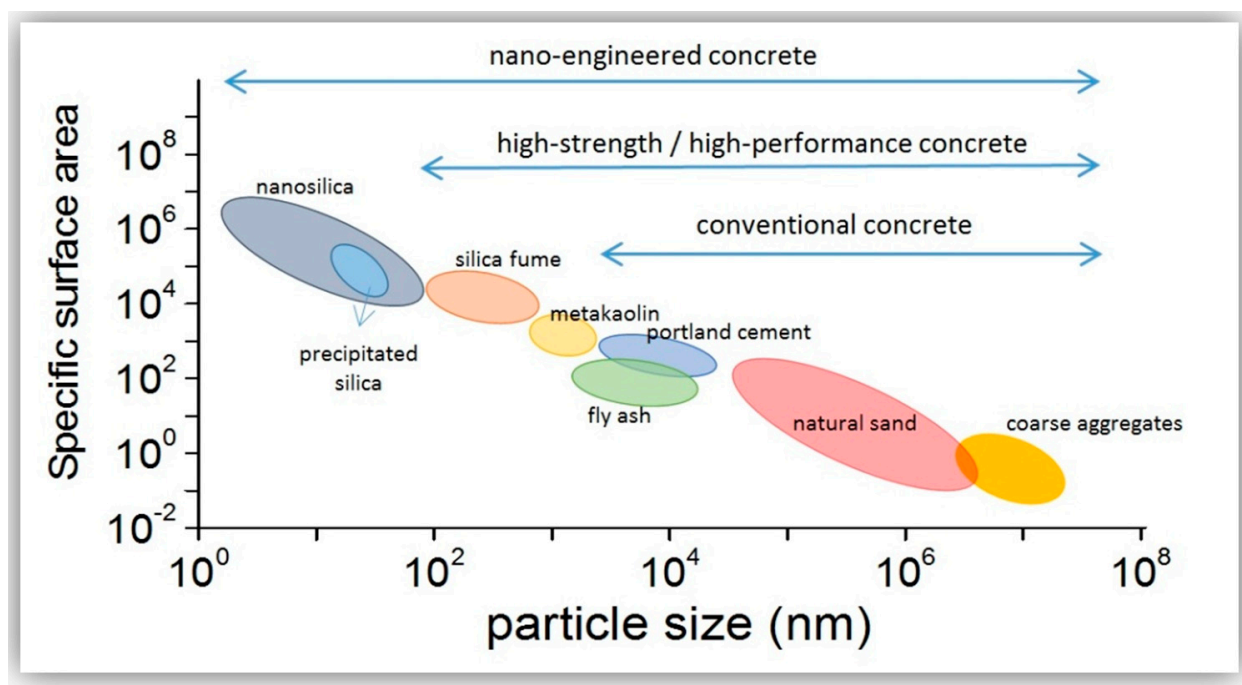

Figure 3. Some kinds of differently-sized particles used for asphalt concrete production.

If Portland cement aggregates, fly ashes, natural sands and coarse aggregates are involved in conventional asphalt concretes, more finely-subdivided particles (size $10 \mathrm{~nm}$ and above) like metakaolin, finely ground mineral additives and silica fumes are employed in the production of high strength/high performance concrete. Recently, even smaller particles (down to $1 \mathrm{~nm}$ ) and mesoporous materials with large surface area $\left(5-100 \mathrm{~m}^{2} / \mathrm{g}\right)$, have been employed in nano-engineered asphalt concretes.

Since there are clear differences among all the disciplines involved in the study of nanostructured materials, it is evident that nanotechnology applied to bitumens is a complex structure of interconnected research areas. It follows, and we strongly support this, that synergic co-operation among researchers with different skills is to be considered pivotal making nanosciences definitely multidisciplinary, an aspect which cannot be absent in modern research in general [36].

\subsection{A Problem Arises: Nanoparticles Tend to Aggregate}

The use of nanoparticles poses however a problem. Due to the general incompatibility between the chemical nature of the bitumen and that of the inorganic particles, a tendency of nanoparticle aggregation/separation is observed. This will be seen afterwards, when the solution to functionalize nanoparticle surface will be discussed in Section 5 entitled "An expensive solution: organic-modification of inorganic nanoparticle surfaces".

Although detailed discussions on the possible mechanisms of nanoparticle growth/aggregation can be found in the literature [37,38], it is important to simply point out here is that the driving force of any growth process is the attempt of surface atoms to form bonds to complete their coordination structure so it can be expected that the more efficient is the saturation of surface dangling bonds by growing, the more powerful the driving force is. The variation of the number of surface atoms with increasing the particles size is then represented by the size derivative of the fraction of surface atoms, reported in Figure 2, upper panel.

This force diminishes very rapidly with size but, increasing the nanoparticle size, their peculiar characteristics are progressively lost. It is now obvious that the use of nanoparticles in bitumen technology must involve the size control. This is, indeed, what is generally done by the functionalization of nanoparticle surface.

Thus, not only must the method for nanoparticle preparation take into account the final nanoparticle size, but also a method for their stabilization should be taken into account, thus involving an obvious 
cost increase. The costs to improve bitumens properties with the addition of nanoparticles are not trivial at all, and can make the difference between an affordable method or not. Some comments about the costs are therefore the topic of the following section.

\section{The Main Drawback: the Costs}

This is a crucial point: at what extent a given technological field can bear the costs of reducing the size? Each size regime has specific properties and can give application-specific added-value, so it is not true that smaller means better. There is a delicate equilibrium among properties, costs and added value to be taken into account.

At current prices, for the nanomodifications to be cost effective, a significant improvement in durability has to be attained. It is expected that the production of nanoparticles in bulk quantity and the use of alternative sources will significantly reduce the costs. For example, rice husk, an abundant waste biomass with high content of silica was identified as a potential low-cost resource for the production of nanosilica particles [39]. Therefore, it is necessary to carry out economic, ecological and environmental evaluations of nanomodified asphalt before a large-scale application in practical engineering.

The use of nanoparticles implies costs which make nanoparticles-additivated bitumens and asphalts much more expensive. The costs involved in bitumen and asphalt productions depend on different factors as depicted by Martinho et al. [40]. However, they are of the order of 3-350 (€/ton) for common bitumens/asphalts as listed in Table 1

Table 1. Cost evaluation of typical asphalt mixtures.

\begin{tabular}{cc}
\hline Materials & Average Unit Prices (€/ton) \\
\hline Bitumen 35/50 & 350 \\
Natural aggregates & 10 \\
Electric arc furnace steel slag aggregates & 3 \\
Reclaimed asphalt pavement aggregates & 5 \\
Recycled concrete aggregate & 5 \\
\hline
\end{tabular}

In comparison to this, the cost of nanomaterials to be used as asphalt additives is much higher. This is due to the use of expensive equipment and technology and the highly qualified personal involved and so on.

Products with high purity and narrow size range and high specific surface may demand higher processing efforts, higher complexity of the apparata involved and higher skills of the people involved, thus implying higher final costs. For this reason, it is not possible to define a cost for a given nanomaterial, but only a rough range. Mind that the prices for nanoparticles are not given in $€$ /ton like for bitumens, but in $€ / \mathrm{kg}$ or even in $€ / \mathrm{g}$ ! Let us examine Table 2, which reports some indicative ranges for nanoparticle costs, for some comments. From a perusal of Table 2 it can be seen that the cheapest material is nanosilica, which can cost down to $80 € / \mathrm{kg}$ (see $0.08 € / \mathrm{g}$, first entry in the table). However, its surface modification to increase its compatibility with the apolar nature of the bitumen increases the cost a lot, so a silane-modified nanosilica cost between $180 € / \mathrm{kg}$ to $450 € / \mathrm{kg}$. If organic particles are used the cost increases severely: the most expensive family of such nanomaterials is that of single walled nanotubes, whose cost can span from $65 € / g$ to about $200 € / g$. Multiwalled carbon nanotubes (MWCNTs) are cheaper, ranging from about $2 € / g$ up to $40 € / g$. Among the organic carbon nanostructures, however, carbon nanofibers and nanoplatelets are the most affordable solutions, since their cost hardly exceeds $15 € / g$ [41].

Of course, specialized technology development and the increasing market of carbon and graphene families will cause a decrease in their price, probably making such kind of materials more appealing for bitumen and asphalt modification. However, at the moment, the use of inorganic nanoparticles is still the most affordable solution. 
Table 2. Costs of inorganic and organic nanoparticles used as additive in bitumens and asphalt concrets; (a) Laser Synthesized; (b) from [42]; (c) from [43].

\begin{tabular}{|c|c|c|}
\hline & Materials & Unit Price $(€ / g)$ \\
\hline \multirow{7}{*}{ Inorganic nanoparticles } & Nano $\mathrm{SiO}_{2}$ & $\begin{array}{c}40(\mathrm{a}) \\
0.08-0.15(\mathrm{~b}) \\
1.6-6.5(\mathrm{c})\end{array}$ \\
\hline & Nano Iron & $\begin{array}{c}4.8-17 \\
0.1-2.6(b)\end{array}$ \\
\hline & $\mathrm{Fe}_{2} \mathrm{O}_{3}$ & $\begin{array}{c}3.4 \\
0.1-0.3(\mathrm{~b}) \\
4.42-11.5(\mathrm{c})\end{array}$ \\
\hline & Nano ZnO & $\begin{array}{c}1.48 \\
1.23-1.94(\mathrm{c}) \\
\end{array}$ \\
\hline & Nano $\mathrm{CuO}$ & $\begin{array}{c}2-7.2 \\
1.24-9.8 \text { (c) }\end{array}$ \\
\hline & Nano $\mathrm{Al}_{2} \mathrm{O}_{3}$ & $\begin{array}{c}1.8-9 \\
1.3-6.9 \text { (c) }\end{array}$ \\
\hline & Nanoclay (800 nm) & 1.16 \\
\hline \multirow{7}{*}{ Organic nanoparticles } & Single Walled CNT (SWCNT) & $\begin{array}{c}65-195 \\
54.7-263 \text { (c) } \\
\end{array}$ \\
\hline & Double Walled CNT (DWCNT) & $\begin{array}{c}43 \\
51.21(\mathrm{c})\end{array}$ \\
\hline & Multiwalled CNT (MWCNT) & $\begin{array}{c}1.5-33 \\
30.9-34.4(\mathrm{c}) \\
\end{array}$ \\
\hline & Graphene Nanoplatelets (GNP) & $\begin{array}{c}6-11 \\
15-114 \text { (c) }\end{array}$ \\
\hline & Graphene Oxide (GO) & $\begin{array}{l}68-165 \\
172(\mathrm{c})\end{array}$ \\
\hline & Reduced Graphene Oxide (rGO) & 48 \\
\hline & Carbon Nanofibers (CNF) & $\begin{array}{c}14 \\
65(\mathrm{c})\end{array}$ \\
\hline
\end{tabular}

\section{A Cheap Solution: The Use of Inorganic Nanoparticles to Improve Mechanical Properties}

Nanosilica is probably one of the cheapest materials among all the nano-sized ones, and this renders its use quite affordable, due to its high stability, ability to disperse, filler effect and its pozzolanic reactivity [44,45]. Besides, the rutting resistance, fatigue cracking and anti-stripping properties are enhanced [46].

Several authors have added nano- $\mathrm{SiO}_{2}$ to a bare bitumen to demonstrate enhancement of performance (softening point increases according to the nanosilica content, while penetration decreases) as well as a clear improvement in storage stability [47]. Zghair et al. [48] self-consistently found that the penetration value and the ductility decrease with the amount of nanosilica whereas the softening temperature and rotational viscosity increase.

The effect of silica is clear also in the increase of the Marshall stability and of resistance against rutting at loading conditions, as well as the fatigue life of warm mix asphalts as found by Galooyak et al. [49], They conclude that increasing mixing times would positively affect the properties of the binder, because, obviously, longer times can guarantee a better dispersion. However, as the authors correctly point out, this would increase the energy consumption and consequently the costs.

As Crucho et al. themselves admit [50], nanosilicas are the most studied materials as asphalt binder modifiers. This is unavoidable, in our opinion, due to the low cost and the ease of supply. Despite the wide use of nanosilica, however, comparative studies among different kinds of nanoparticles are also 
important: thanks to comparative studies, in fact, it was found that nano- $\mathrm{TiO}_{2}$ has more problems than nano-SiO ${ }_{2}$ in chemical compatibility with the apolar bitumen [51] while hydrophilic bentonite and Zero-valent nano-iron have better affinity with bitumens [50].

Specific influences of nano- $\mathrm{TiO}_{2}, \mathrm{ZnO}, \mathrm{Al}_{2} \mathrm{O}_{3}$ and $\mathrm{Fe}_{2} \mathrm{O}_{3}$ in the creep rate and strain modulus of hot mix asphalt have been also highlighted [52]. Nano-CuO was, instead, found to enhance resistance to rutting deformations of bitumens and aged bitumens but only at temperatures lower than $64{ }^{\circ} \mathrm{C}$ [53]. The authors also found that the addition of nano- $\mathrm{CuO}$ to bitumen enhances its fatigue cracking, while other authors have found that nano- $\mathrm{CuO}$ can be used as phase change material to increase thermal properties (glass transition temperature, melting peak temperature, specific heat capacity) [54].

Nazari and other co-workers [55] explored the potential of $\mathrm{CaCO}_{3}$ nanoparticles, besides those of $\mathrm{SiO}_{2}$ and $\mathrm{TiO}_{2}$. Confirming that silica are the particles giving greatest fatigue resistance, the authors detected a possible antioxidant effect of nano- $-\mathrm{TiO}_{2}$ and nano- $\mathrm{CaCO}_{3}$.

A similar comparative study among $\mathrm{SiO}_{2}, \mathrm{TiO}_{2}$ and $\mathrm{CaCO}_{3}$ nanoparticles was conducted with F.M. Nejad [52] who confirmed that the major effect was found with nanosilica, probably due to its higher specific surface and lower density (which probably gives a higher volume fraction in the bitumen at parity of $w / w \%)$.

In this scenario, an interesting class of nanosilicates is surely nanoclays. They are hydrated silicates with a sheet-like geometry. For this reason, such hydrated silicates are generally known as phyllosilicates [56] (from the Greek phillon, leaf). Phyllosilicate sheets are made up of repeating units of six-membered rings, in turn made up of the $\mathrm{SiO}_{4}$ tetrahedral units. Each ring is shared with the other three oxygen atoms [57].

It is a low-cost material, in fact easily available as residual clay (originated from the surface erosion of rocks or sedimentary rocks) or as transported clay (that is, due to atmospheric agents, removed from the original deposit site and transported far away) [56]. For this reason, clay has always been one of the most used materials in construction. In this context, it was found that bitumen can be reinforced with nanoclay particles since they confer increased stiffness and resistance against aging as well as improved elastic properties [58].

Due to the generally high costs involved in the use of nanoparticles, a brilliant idea is that of Hussein et al. [59], who wanted to reuse the waste from the ceramic material industries as possible modifiers for bitumen. They crushed the powder, sieved it at $75 \mu \mathrm{m}$, and heated it for $30 \mathrm{~min}$ at $130{ }^{\circ} \mathrm{C}$ for water elimination, and finally grounded it using a milling bowl. Consistently with other authors, they found that the presence of nanoparticles caused a decrease in penetration, an increase in softening temperature and an improvement in resistance to rutting. However, due to the nanoparticles' high surface energy, the authors found that their agglomeration is favoured. This aspect has been shown from a theoretical point of view, using simple chemical reasoning, in Section 2.4 entitled "A Problem Arises: Nanoparticles Tend to Aggregate".

\section{An Expensive Solution: Organic-Modification of Inorganic Nanoparticle Surface}

As the eager reader has probably already observed, some authors have reported problems in the chemical compatibility of the nanoparticles [51] and nanoparticles' tendency to agglomerate due to the high surface energy [59]. To solve this problem, an expensive but effective solution is represented by functionalization of the nanoparticle surface to change its chemical nature, making it more compatible with the apolar nature of the host matrix (bitumen, asphalt) thus avoiding instability problems.

The role of aluminium oxide nanoparticles in the rheological properties of bitumen modified with acrylonitrile styrene acrylate (ASA) polymer was investigated by Mubaraki et al. [60]. An increase in viscosity, softening point temperatures and in storage stability and resistance against rutting were found. Nano-montmorillonite (size 1-2 nm), after organomodification to make it organophilic for a better dispersion in bitumen, was tested by Sedaghat et al. [61].

The functionalization of silica nanoparticles with (3-aminopropyl) triethoxysilane (APTES) can favour their dispersion (probed by SEM) within the bituminous matrix, and consequently improve their 
performance (reduction of the chemical aging index-CAI—for carbonyl and sulfoxide groups, higher rutting parameter and lower cracking parameter) [62]. The same authors explored the possibility to combine different coupling agents to minimize nanoparticle agglomeration [63].

Effectiveness of surface functionalization was confirmed by Li et al. [64] who found that a better dispersion of the nano- $\mathrm{ZnO}$ inside the bitumen is achieved if nanoparticles are silano-modified at the surface (FT-IR checks if the silano-modification is effective). Surface treatment of nano-SiO $\mathrm{S}_{2}$, nano- $\mathrm{TiO}_{2}$ and nano-ZnO with $\gamma$-(2,3-epoxypropoxy) propyltrimethoxysilane as silane coupling agent to modify the nanoparticles' surfaces was performed by Zhang et al. [65]. Similar clues were found by Chen et al. in 2015 [66].

In general, it is now quite clear that the surface modification improves the dispersion. A worth of note is the work by Sun et al. [67], who used modified nanoparticles (seven different nanoparticles: $\mathrm{SiO}_{2} ; \mathrm{CaCO}_{3} ;$ montmorillonite; $\mathrm{TiO}_{2} ; \mathrm{Fe}_{2} \mathrm{O}_{3} ; \mathrm{ZnO}$ and bentonite with size in the range 15-30 nm functionalized with silane stearic acid or polyethylenimmine). They demonstrated how modification can give better performances (softening point and viscosity general increase, parallel to decrease in ductility) especially at high temperatures. It is important to note, in our opinion, how the authors are convinced about the importance of the surface modification to influence the final material properties. Probably for this reason, in fact, these authors improved the methodology for surface modification of nanoparticles. The previous procedure involved dosing the coupling agents on the amount of bitumen; instead, in their new procedure the percentage by weight of coupling agents is calculated with respect to the quantity of nano- $\mathrm{SiO}_{2}$. In doing so, they discovered the optimal amount of coupling agent with consequent benefits procedure efficiency.

\section{Novel Materials: Organic Nanoparticles}

The problem of chemical compatibility between nanoparticles and the bitumen/asphalt can be solved also if organic nanoparticles are used. This is in our opinion a brilliant solution since in this way the cost of the surface functionalization of inorganic nanoparticles is also avoided.

Chen et al. [66] found that organic expanded vermiculite compounds (OEVMT) give better resistance to fatigue and higher thermal stability with respect to nano- $-\mathrm{TiO}_{2}$ and nano- $\mathrm{ZnO}$ modified on the surface by $\Upsilon$-(2,3-epoxypropoxy)propyltrimethoxysilane, even if inorganic nanoparticles nano- $\mathrm{TiO}_{2}$ showed better resistance to photo-oxidation and, consequently, better anti-aging effect due to their semiconductor nature. However, for further comments on the photo-protection effect given by nanoparticles see below the section about "Added-Values Given by the Use of Nanoparticles". In similar way, Zhang et al. [68] found that OEVMT, treated with star quaternary alkylammonium chloride to modify its interlayers from hydrophilic to lipophilic, can contrast the thermo-oxidative aging. Another interesting class of organic nanoparticles is that of carbon nanostructures: graphenes, nanotubes and nanofibers. Such nanostructures are schematically depicted in Figure 4. Their main use is in electronics-related applications like in flexible electronic and optoelectronic devices [69] or as electrodes and buffer layers component in polymer solar cells (PSCs) [70], but they were found to behave like reinforcing fillers in composites, photochemical cells, etc. [71]. This "filling" behavior can be transferred from to the fields of construction materials [72-75]. 

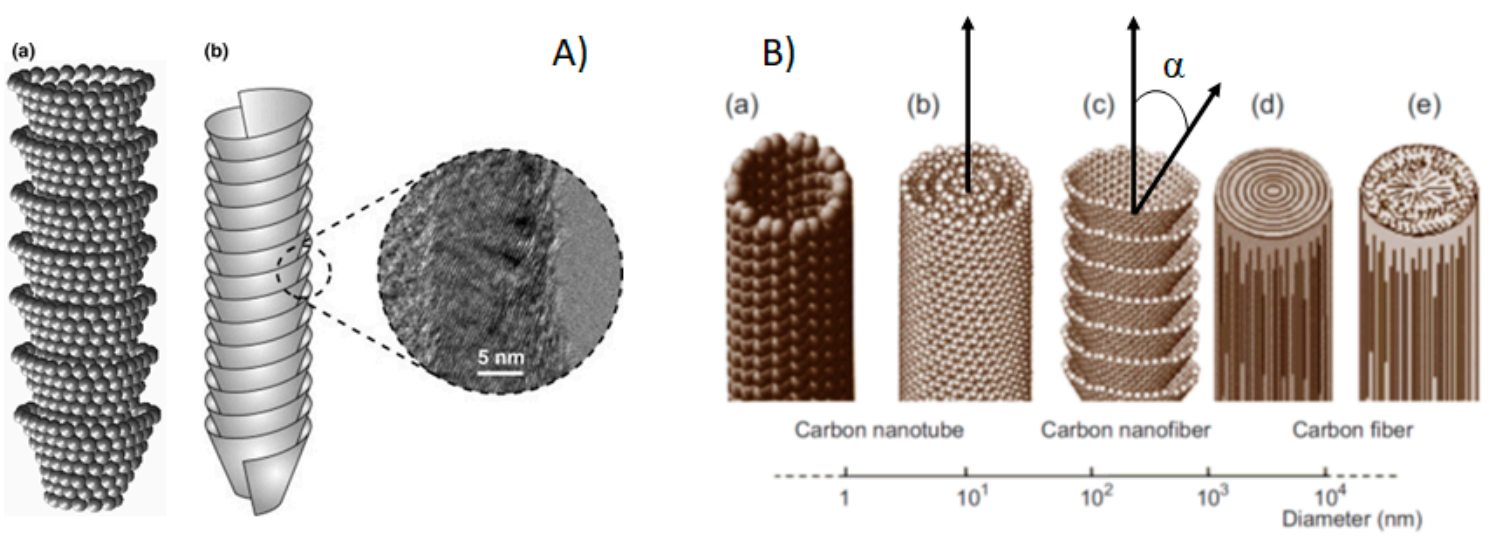

Figure 4. Panel (A): (a) 3D representation of cup-stacked graphene layers in a single CNF, and (b) Simplified schematic of stacked-cup carbon nanofiber helical structure with inset showing TEM image of inclined orientation of grapheme planes along the side of structure with respect to nanofiber axis. Image taken from [76]. Courtesy of Elsevier. Panel (B): Schematic of size and morphology distribution of various nanotubular structures that shows the main difference in the structure between carbon nanofibers and carbon nanotubes. (a) single wall carbon nanotube, (b) multi walled carbon nanotube, (c) carbon nanofiber, $(d, e)$ carbon fibers of different complexity. Reprinted from [68].

Generally, the use of nanostructured carbon materials gives more durable substrates [77], so, for example, graphene was used as modifier in bitumens [78,79] conferring increased stiffness and improving elastic behavior. However, the main drawback of the use of graphene as a bitumen modifier-and more generally as an element to improve the mechanical performances of construction materials-is its high production cost. For this reason, the studies on grapheme are very few and have been shifted toward graphene-derived nanomaterials like graphene oxide (GO) [80], and graphene nanoplatelets (GNPs) $[81,82]$ or some cheap carbon nanotubes and carbon nanofibers. The general structure of carbon nanotubes and carbon nanofibers is shown in Figure 4A. Carbon nanotubes were found to give stiffness increase and strain decrease regardless of the stress applied [83] improving also the mechanical performance of hot mix asphalt (HMA). Multi-walled carbon nanotubes (MWNTs) were used by Loise et al. to improve the rheological properties of bitumen [84]. In this case, the authors hypothesize that higher defectiveness in MWNTs gives better improvement of the rheological properties, due to a probable formation of networks bridged by MWNTs defects. Finally, an increase by a factor of $2-3$ in the fatigue life of bitumens modified with carbon nanofibers and improved characteristics of hot mix asphalts were found by Khattak et al. [85] who, highlighting the actual requirement of huge amounts of solvents to disperse CNFs, advise of the need to explore more eco-friendly mixing techniques to use lower amounts of solvents.

In conclusion, there is no doubt that organic nanoparticles have a chemical nature intrinsically compatible with that of bituminous materials, and that their use avoids the costs of further steps consisting in the chemical modification of nanoparticle surface, like in the case of inorganic nanoparticles. However, their cost is still high in some cases (graphenes, nanotubes). The increasing market of carbon and graphene families and the technology development specialized in the production of such kind of materials will cause a decrease in their price, probably making carbon nanostructures more appealing for large-scale applications like in bitumen and asphalt modification.

\section{Added-Values Given by the Use of Nanoparticles}

There are numerous examples showing that the addition of nanoparticles within the bitumens or asphalts confers specific properties of certain added values. For example, hot mix asphalt mixtures modified with carbon nanofibers can give piezoresistive responses [86].

Modification of bitumens with nanoclays (montmorillonite) reduces their flammability. In this way, bitumen can move from a "fuel" classification to a "self-extinguishing" classification [87]. The proposed 
mechanism of action is interesting: nanoclays can catalyse char-forming reactions producing charred residues which are able to delay the escape of volatile products and the penetration of oxygen thus hindering combustion.

Nano-zinc oxide can also behave like an antistripping agent in hot mix asphalt (HMA) with limestone and granite as aggregates [88]. It was found, in fact, that nano- $\mathrm{ZnO}$ decreases the acidity of the bitumen thus favouring the adhesion between the bitumen itself and acid aggregates, such as granite. In this way, nano- $\mathrm{ZnO}$ improves the adhesion between the bitumen and the aggregates, especially in the case of moisture-conditioned samples.

Another very interesting added value provided by the addition of nanoparticles is the protection against aging. Aging effect, indeed, is particularly severe in surface layers that are exposed to environmental conditions such as UV radiation, moisture, oxygen, and temperature changes [89]. In this ambience, even if there are examples of uses of very expensive materials like silver nanoparticles [90] to contrast oxidative aging, nano- $\mathrm{TiO}_{2}$ and nano- $\mathrm{CaCO}_{3}$ were found to have a possible antioxidant action [55]. However, another interesting effect is that provided by semiconductor nanoparticles in the screening of UV-radiation. Thus, nano- $\mathrm{ZnO}$ was found to give good resistance of modified bitumens to the UV aging, although Du et al. [91] found that their effect depends on the bitumen nature. The potential of $\mathrm{ZnO}$ nanoparticles to increase the resistance of bitumen to ultraviolet aging was also studied by Li et al. [64] and Zhang et al. [65].

Since some semiconductor nanoparticles have some problems in chemical compatibility with the apolar bitumen [51], other authors modified their surface to better disperse nanoparticles within the bituminous matrix $[65,67]$.

The problems of obtaining a better distribution of nanoparticles come above all from the chemical reasoning that asphalt concretes are heterogeneous materials: there are composed of aggregates, nanoparticles, bitumen and pores; sometimes there are also networks, so the mechanical properties depend also on the form and the distribution of the aggregates. Some more comments are given below, in Section 8.2 entitled "How to Probe the Distribution of Nanoparticles: Nanotomography as One of the Techniques of Election".

However, in the case of semiconductor nanoparticles, we want to stress another aspect which in our opinion has to be taken into account for. Semiconductor nanoparticles have basically two effects whose relative contributions are in complex competition: (i) their semiconductor nature allows absorption of those radiations whose energies are above the energy gap value and (ii) the size in the nano-regime allows radiation scattering within the sample.

Our opinion is supported by the observation, made by Chen et al. [65], that 3\% w/w of nanoparticles is the optimum amount of nanoparticles in giving resistance to photo-oxidation, but $1 \%$ of nanoparticles gives worse behaviour even with respect to the reference bitumen. This is consistent with the competition of two opposite effects.

We think that at low nanoparticle concentration a detriment effect can arise as a result of the scattering contribution of the nanosized particles which helps in diffusing the radiation within the sample. This effect is not counterbalanced enough by the absorption contribution of such nanoparticles which would help in depleting radiation. So, at nanoparticles concentrations higher enough, the absorption effect can overcome the scattering contribution and so effective photo-screening and protection of the matrix can take place.

It is obvious that the capability of nanoparticles to absorb photons must be exactly determined for a wisely-designed bitumen, and this requires suitable techniques for nanoparticle characterization. For this aspect we will give some hints, comments and perspectives in Section 8.3 entitled "UV-Vis absorption for probing bitumen screening towards UV radiation". A scheme of the techniques used with the corresponding references is reported in Table 3. 
Table 3. A panoramic view of the techniques used for investigating nanoparticles-containing bitumens and asphalts.

\begin{tabular}{|c|c|c|c|}
\hline Techniques & Authors & Bitumen Matrix & Nano-Materials \\
\hline \multirow{14}{*}{$\begin{array}{l}\text { X-Ray Diffraction } \\
\text { (XRD) }\end{array}$} & Jahromi et al. (2009) [58] & Fresh, short-term aged, long-term aged & Clay (closite and nanofil) \\
\hline & Wu et al. (2009) [87] & Fresh, short-term aged, long-term aged & Clay (montmorillonite) \\
\hline & Zhang et al. (2015) [67] & Fresh, long-term aged, UV aged & $\mathrm{ZnO}$ \\
\hline & Chen et al. (2015) [66] & Fresh, short-term aged, long-term aged, UV aged & $\mathrm{SiO}_{2}, \mathrm{TiO}_{2}, \mathrm{ZnO}$ \\
\hline & Nazari et al. (2018) [55] & Fresh, short-term aged, long-term aged & $\mathrm{SiO}_{2}, \mathrm{TiO}_{2}, \mathrm{CaCO}_{3}$ \\
\hline & Loise et al. (2019) [84] & Fresh & Carbon nanotubes \\
\hline & Sedaghat et al. (2020) [61] & Fresh, short-term aged, long-term aged & Clay (montmorillonite) \\
\hline & Hussein et al. (2017) [59] & Fresh & Ceramic powder \\
\hline & Li et al. (2018) [92] & Fresh, SBS modified & Graphene oxide \\
\hline & Zhang et al. (2015) [68] & Fresh, long-term aged, UV aged & $\mathrm{ZnO}$ \\
\hline & Du et al. (2015) [91] & Fresh, short-term aged, UV-aged & $\mathrm{ZnO}$ \\
\hline & Li et al. (2015) [64] & Fresh, short-term aged, UV-aged & $\mathrm{ZnO}$ \\
\hline & Ali et al. (2017) [93] & Fresh & $\mathrm{Al}_{2} \mathrm{O}_{3}$ \\
\hline & Sun et al. (2017) [67] & Fresh, asphalt mixture & $\mathrm{SiO}_{2}, \mathrm{TiO}_{2}, \mathrm{CaCO}_{3}, \mathrm{ZnO}$, montmorillonite, bentonite, $\mathrm{Fe}_{2} \mathrm{O}_{3}$ \\
\hline \multirow{8}{*}{$\begin{array}{l}\text { Fourier-Trasform Infra-Red Spectroscopy } \\
\qquad \text { (FTIR) }\end{array}$} & Hussein et al. (2017) [59] & Fresh & Ceramic powder \\
\hline & Olabemiwo et al. [90] & Fresh & $\mathrm{Ag}$ \\
\hline & Amini and Hayati (2020) [54] & Fresh, short and long term aged & $\mathrm{CuO}$, carbon nanotubes \\
\hline & Li et al. (2018) [92] & Fresh, SBS modified & Graphene oxide \\
\hline & Nazari et al. (2018) [55] & Fresh, short-term aged, long-term aged & $\mathrm{SiO}_{2}, \mathrm{TiO}_{2}, \mathrm{CaCO}_{3}$ \\
\hline & Liu et al. (2018) [94] & Fresh, WMA, HMA & Graphene oxide \\
\hline & Karnati et al. (2019) [62] & Fresh, long-term aged & $\mathrm{SiO}_{2}$ \\
\hline & Karnati et al. (2020) [63] & Fresh, aged & $\mathrm{SiO}_{2}$ \\
\hline \multirow{3}{*}{$\begin{array}{l}\text { Atomic Force Microscopy } \\
\text { (AFM) }\end{array}$} & Zhang et al. (2015) [65] & Fresh, long-term aged, UV aged & $\mathrm{ZnO}$ \\
\hline & Du et al. (2015) [91] & Fresh, short-term aged, UV-aged & $\mathrm{ZnO}$ \\
\hline & Hussein et al. (2017) [53] & Fresh & Ceramic powders \\
\hline \multirow{12}{*}{$\begin{array}{l}\text { Scanning Electron Microscopy } \\
\text { (SEM) }\end{array}$} & Arabani et al. (2015) [83] & HMA & Carbon nanotubes \\
\hline & Taherkani et al. (2016) [87] & Fresh & $\mathrm{SiO}_{2}$ \\
\hline & Nejad et al. (2016) [95] & Fresh, HMA & $\mathrm{TiO}_{2}, \mathrm{ZnO}, \mathrm{Al}_{2} \mathrm{O}_{3}, \mathrm{Fe}_{2} \mathrm{O}_{3}$ \\
\hline & Shafabakhsh et al. (2018) [53] & Fresh, short-term aged, long-term aged & $\mathrm{CuO}$ \\
\hline & Nazari et al. (2018) [55] & Fresh, short-term aged, long-term aged & $\mathrm{SiO}_{2}, \mathrm{TiO}_{2}, \mathrm{CaCO}_{3}$ \\
\hline & Yang et al. (2020) [96] & Fresh & Carbon nanotube sponges \\
\hline & Amini and Hayati (2020) [54] & Fresh, short and long term aged & $\mathrm{CuO}$, carbon nanotubes \\
\hline & Ali et al. (2017) [93] & Fresh & $\mathrm{Al}_{2} \mathrm{O}_{3}$ \\
\hline & Karnati et al. (2019) [62] & Fresh, long-term aged & $\mathrm{SiO}_{2}$ \\
\hline & Karnati et al. (2020) [63] & Fresh, aged & $\mathrm{SiO}_{2}$ \\
\hline & Li et al. (2015) [64] & Fresh, short-term aged, UV aged & $\mathrm{ZnO}$ \\
\hline & Sun et al. (2017) [67] & Fresh, asphalt mixture & $\mathrm{SiO}_{2}, \mathrm{TiO}_{2}, \mathrm{CaCO}_{3}, \mathrm{ZnO}$, montmorillonite, bentonite, $\mathrm{Fe}_{2} \mathrm{O}_{3}$ \\
\hline
\end{tabular}


Table 3. Cont

\begin{tabular}{|c|c|c|c|}
\hline Techniques & Authors & Bitumen Matrix & Nano-Materials \\
\hline \multirow{4}{*}{ UV spectroscopy } & Zhang et al. (2015) [68] & Fresh, long-term aged, UV aged & $\mathrm{ZnO}$ \\
\hline & Amini and Hayati (2020) [54] & Fresh, short and long term aged & $\mathrm{CuO}$, Carbon nanotubes \\
\hline & Li et al. (2015) [64] & Fresh, short-term aged, UV aged & $\mathrm{ZnO}$ \\
\hline & Zhang et al. (2015) [68] & Fresh, UV aged & $\mathrm{SiO}_{2}, \mathrm{TiO}_{2}, \mathrm{ZnO}$ \\
\hline \multirow{12}{*}{ Rotational viscosity } & Zhang et al. (2015) [68] & Fresh, long-term aged, UV aged & $\mathrm{ZnO}$ \\
\hline & Du et al. (2015) [91] & Fresh, short-term aged, UV-aged & $\mathrm{ZnO}$ \\
\hline & Li et al. (2015) [58] & Fresh, short-term aged, UV aged & $\mathrm{ZnO}$ \\
\hline & Nejad et al. (2016) [95] & Fresh, HMA & $\mathrm{TiO}_{2}, \mathrm{ZnO}, \mathrm{Al}_{2} \mathrm{O}_{3}, \mathrm{Fe}_{2} \mathrm{O}_{3}$ \\
\hline & Mubaraki et al. (2016) [60] & Fresh & $\mathrm{Al}_{2} \mathrm{O}_{3}$ \\
\hline & Ali et al. (2017) [93] & Fresh & $\mathrm{Al}_{2} \mathrm{O}_{3}$ \\
\hline & Liu et al. (2018) [94] & Fresh, WMA, HMA & Graphene oxide \\
\hline & Karnati et al. (2019) [62] & Fresh, long-term aged & $\mathrm{SiO}_{2}$ \\
\hline & Karnati et al. (2020) [63] & Fresh, aged & $\mathrm{SiO}_{2}$ \\
\hline & Zghair et al. (2020) [48] & Fresh & $\mathrm{SiO}_{2}$ \\
\hline & Sedaghat et al. (2020) [61] & Fresh, short-term aged, long-term aged & Clay (montmorillonite) \\
\hline & Li et al. (2018) [92] & Fresh, SBS modified & Graphene oxide \\
\hline \multirow{2}{*}{ RAMAN Spectroscopy } & Moreno-Navarro et al. (2018) [78] & Fresh & Graphene \\
\hline & Loise et al. (2019) [84] & Fresh & Carbon nanotubes \\
\hline \multirow{3}{*}{ Limiting oxygen index methods } & Wu et al. (2009) [87] & Fresh, short-term aged, long-term aged & Clay (montmorillonite) \\
\hline & Wu et al. (2009) [87] & Fresh, short-term aged, long-term aged & Clay (montmorillonite) \\
\hline & Sun et al. (2017) [67] & Fresh, asphalt mixture & $\mathrm{SiO}_{2}, \mathrm{TiO}_{2}, \mathrm{CaCO}_{3}, \mathrm{ZnO}$, Montmorillonite, bentonite, $\mathrm{Fe}_{2} \mathrm{O}_{3}$ \\
\hline \multirow{6}{*}{ Differential Scanning Calorimetry (DSC) } & Nejad et al. (2017) [52] & Fresh & $\mathrm{SiO}_{2}, \mathrm{TiO}_{2}, \mathrm{CaCO}_{3}$ \\
\hline & Amini and Hayati (2020) [54] & Fresh, short and long term aged & $\mathrm{CuO}$, Carbon nanotubes \\
\hline & Liu et al. (2018) [94] & Fresh, WMA, HMA & Graphene oxide \\
\hline & Yang et al. (2020) [96] & Fresh & Carbon nanotube sponges \\
\hline & Ghasemi et al. (2012) [47] & Fresh, HMA & $\mathrm{SiO}_{2}$ \\
\hline & Galooyak et al. (2015) [49] & Fresh, WMA & $\mathrm{SiO}_{2}$ \\
\hline \multirow[t]{3}{*}{ Indirect Tensile Stress (ITS) } & Amini and Hayati (2020) [54] & Fresh, short and long term aged & $\mathrm{CuO}$, carbon nanotubes \\
\hline & Hamedi et al. (2016) [88] & Fresh, HMA & $\mathrm{ZnO}$ \\
\hline & Crucho et al. (2018) [50] & Fresh, asphalt mixture & $\mathrm{SiO}_{2}$, zero-valent iron, clay \\
\hline \multirow{2}{*}{ Performance grade (PG) } & Brcic (2016) [97] & Fresh, short-term aged, long-term aged & Graphene \\
\hline & Sedaghat et al. (2020) [61] & Fresh, short-term aged, long-term aged & Clay (montmorillonite) \\
\hline \multirow{3}{*}{ Thermo Gravimetric Analysis (TGA) } & Loise et al. (2019) [84] & Fresh & Carbon nanotubes \\
\hline & Yang et al. (2020) [96] & Fresh & Carbon nanotube sponges \\
\hline & Li et al. (2018) [92] & Fresh, SBS modified & Graphene oxide \\
\hline
\end{tabular}


Table 3. Cont

\begin{tabular}{|c|c|c|c|}
\hline Techniques & Authors & Bitumen Matrix & Nano-Materials \\
\hline \multirow{3}{*}{ Storage stability } & Zhang et al. (2015) [65] & Fresh, UV aged & $\mathrm{SiO}_{2}, \mathrm{TiO}_{2}, \mathrm{ZnO}$ \\
\hline & Mubaraki et al. (2016) [60] & Fresh & $\mathrm{Al}_{2} \mathrm{O}_{3}$ \\
\hline & Ali et al. (2017) [93] & Fresh & $\mathrm{Al}_{2} \mathrm{O}_{3}$ \\
\hline \multirow{2}{*}{ Transmission Electron Microscopy (TEM) } & Hussein et al. (2017) [59] & Fresh & Ceramic powders \\
\hline & Loise et al. (2019) [84] & Fresh & Carbon nanotubes \\
\hline \multirow{2}{*}{ Indirect Tensile Stiffness Modulus (ITSM) } & Ghasemi et al. (2012) [47] & Fresh, HMA & $\mathrm{SiO}_{2}$ \\
\hline & Arabani et al. (2015) [83] & HMA & Carbon nanotubes \\
\hline \multirow{4}{*}{$\begin{array}{l}\text { X-Ray Fluorescence }(\mathrm{XRF}) \\
\text { Flash point }\end{array}$} & Hussein et al. (2017) [59] & Fresh & Ceramic powders \\
\hline & Nejad et al. (2016) [95] & Fresh, HMA & $\mathrm{TiO}_{2}, \mathrm{ZnO}, \mathrm{Al}_{2} \mathrm{O}_{3}, \mathrm{Fe}_{2} \mathrm{O}_{3}$ \\
\hline & Olabemiwo et al. [90] & Fresh & $\mathrm{Ag}$ \\
\hline & Sadeghnejad et al. (2017) [51] & Fresh & $\mathrm{SiO}_{2}, \mathrm{TiO}_{2}$ \\
\hline \multirow[t]{2}{*}{ Kinematic viscosity } & Sedaghat et al. (2020) [61] & Fresh, short-term aged, long-term aged & Clay (montmorillonite) \\
\hline & Olabemiwo et al. [90] & Fresh & $\mathrm{Ag}$ \\
\hline \multirow{11}{*}{$\begin{array}{c}\text { Pyrolysis-gas } \\
\text { Chromatography test }\end{array}$} & Zeng et al. (2017) [98] & Fresh, short-term aged, long-term aged & Graphene oxide \\
\hline & Jahromi et al. (2009) [58] & Fresh, short-term aged, long-term aged & Clay (closite and nanofil) \\
\hline & Wu et al. (2009) [87] & Fresh, short-term aged, long-term aged & Clay (montmorillonite) \\
\hline & Du et al. (2015) [91] & Fresh, short-term aged, UV-aged & $\mathrm{ZnO}$ \\
\hline & Galooyak et al. (2015) [49] & Fresh, WMA & $\mathrm{SiO}_{2}$ \\
\hline & Chen et al. (2015) [66] & Fresh, short-term aged, long-term aged & $\mathrm{SiO}_{2}, \mathrm{TiO}_{2}, \mathrm{ZnO}, \mathrm{EVMT}$ \\
\hline & Le et al. (2016) [82] & $\begin{array}{l}\text { Fresh, short-term aged, long-term aged, asphalt } \\
\text { mixture }\end{array}$ & Graphene \\
\hline & Brcic (2016) [97] & Fresh, short-term aged, long-term aged & Graphene \\
\hline & Mubaraki et al. (2016) [60] & Fresh & $\mathrm{Al}_{2} \mathrm{O}_{3}$ \\
\hline & Zeng et al. (2017) [98] & Fresh, short-term aged, long-term aged & Graphene oxide \\
\hline & Ali et al. (2017) [93] & Fresh & $\mathrm{Al}_{2} \mathrm{O}_{3}$ \\
\hline \multirow{15}{*}{$\begin{array}{l}\text { Rheology } \\
\text { (performed by means of Dynamic Shear } \\
\text { Rheometer) }\end{array}$} & Sun et al. (2017) [67] & Fresh, asphalt mixture & $\mathrm{SiO}_{2}, \mathrm{TiO}_{2}, \mathrm{CaCO}_{3}, \mathrm{ZnO}$, montmorillonite, bentonite, $\mathrm{Fe}_{2} \mathrm{O}_{3}$ \\
\hline & Nejad et al. (2017) [52] & Fresh & $\mathrm{SiO}_{2}, \mathrm{TiO}_{2}, \mathrm{CaCO}_{3}$ \\
\hline & Sadeghnejad et al. (2017) [51] & Fresh & $\mathrm{SiO}_{2}, \mathrm{TiO}_{2}$ \\
\hline & Hussein et al. (2017) [59] & Fresh & Ceramic powders \\
\hline & Shafabakhsh et al. (2018) [53] & Fresh, short-term aged, long-term aged & $\mathrm{CuO}$ \\
\hline & Amini and Hayati (2020) [54] & Fresh, short and long term aged & $\mathrm{CuO}$, Carbon nanotubes \\
\hline & Li et al. (2018) [92] & Fresh, SBS modified & Graphene oxide \\
\hline & Nazari et al. (2018) [55] & Fresh, short-term aged, long-term aged & $\mathrm{SiO}_{2}, \mathrm{TiO}_{2}, \mathrm{CaCO}_{3}$ \\
\hline & Olabemiwo et al. [90] & Fresh & $\mathrm{Ag}$ \\
\hline & Liu et al. (2018) [94] & Fresh, WMA, HMA & Graphene oxide \\
\hline & Moreno-Navarro et al. (2018) [78] & Fresh & Graphene \\
\hline & Loise et al. (2019) [84] & Fresh & Carbon nanotubes \\
\hline & Karnati et al. (2019) [62] & Fresh, long-term aged & $\mathrm{SiO}_{2}$ \\
\hline & Karnati et al. (2020) [63] & Fresh, aged & $\mathrm{SiO}_{2}$ \\
\hline & Yang et al. (2020) [96] & Fresh & Carbon nanotube sponges \\
\hline
\end{tabular}


Table 3. Cont.

\begin{tabular}{|c|c|c|c|}
\hline Techniques & Authors & Bitumen Matrix & Nano-Materials \\
\hline \multirow{4}{*}{$\begin{array}{l}\text { Rheology } \\
\text { (performed by means of bending beam } \\
\text { rheometer) }\end{array}$} & Le et al. (2016) [82] & $\begin{array}{c}\text { Fresh, short-term aged, long-term aged, asphalt } \\
\text { mixture }\end{array}$ & Graphene \\
\hline & Sun et al. (2017) [67] & Fresh, asphalt mixture & $\mathrm{SiO}_{2}, \mathrm{TiO}_{2}, \mathrm{CaCO}_{3}, \mathrm{ZnO}$, montmorillonite, bentonite, $\mathrm{fe}_{2} \mathrm{O}_{3}$ \\
\hline & Shafabakhsh et al. (2018) [53] & Fresh, short-term aged, long-term aged & $\mathrm{CuO}$ \\
\hline & Amini and Hayati (2020) [54] & Fresh, short- and long-term aged & $\mathrm{CuO}$, carbon nanotubes \\
\hline \multirow{2}{*}{$\begin{array}{l}\text { Gel-Permeation Chromatography (GPC) } \\
\text { Gas Cromatography - Mass spectrometry } \\
\text { (GC-MS) }\end{array}$} & Sun et al. (2017) [67] & $\begin{array}{l}\text { Fresh, asphalt mixture } \\
\text {. }\end{array}$ & $\mathrm{SiO}_{2}, \mathrm{TiO}_{2}, \mathrm{CaCO}_{2} \mathrm{ZnO}$ montmorillonite bentonite, $\mathrm{Fe}_{2} \mathrm{O}_{2}$ \\
\hline & Li et al. (2018) [92] & Fresh, SBS modified & Graphene oxide \\
\hline Surface free energy & Hamedi et al. (2016) [88] & Fresh, HMA & $\mathrm{ZnO}$ \\
\hline Repeated load axial test & Arabani et al. (2015) [83] & HMA & Carbon nanotubes \\
\hline \multirow{2}{*}{ Zeta potential } & Karnati et al. (2019) [62] & Fresh, long-term aged & $\mathrm{SiO}_{2}$ \\
\hline & Karnati et al. (2020) [63] & Fresh, aged & $\mathrm{SiO}_{2}$ \\
\hline \multirow{10}{*}{ Hydrodynamic diameter } & Karnati et al. (2019) [62] & Fresh, long-term aged & $\mathrm{SiO}_{2}$ \\
\hline & Karnati et al. (2020) [63] & Fresh, aged & $\mathrm{SiO}_{2}$ \\
\hline & Jahromi et al. (2009) [58] & Fresh, short-term aged, long-term aged & Clay (closite and nanofil) \\
\hline & Wu et al. (2009) [87] & Fresh, short-term aged, long-term aged & Clay (montmorillonite) \\
\hline & Ghasemi et al. (2012) [47] & Fresh, HMA & $\mathrm{SiO}_{2}$ \\
\hline & Zhang et al. (2015) [68] & Fresh, long-term aged, UV aged & $\mathrm{ZnO}$ \\
\hline & Olabemiwo et al. [90] & Fresh & $\mathrm{Ag}$ \\
\hline & Du et al. (2015) [91] & Fresh, short-term aged, UV aged & $\mathrm{ZnO}$ \\
\hline & Li et al. (2015) [64] & Fresh, short-term aged, UV aged & $\mathrm{ZnO}$ \\
\hline & Zhang et al. (2015) [65] & Fresh, UV aged & $\mathrm{SiO}_{2}, \mathrm{TiO}_{2}, \mathrm{ZnO}$ \\
\hline & Galooyak et al. (2015) [49] & Fresh, WMA & $\mathrm{SiO}_{2}$ \\
\hline \multirow{10}{*}{ (Softening point, Ductility, Penetration) } & Taherkani et al. (2016) [99] & Fresh & $\mathrm{SiO}_{2}$ \\
\hline & Nejad et al. (2016) [95] & Fresh, HMA & $\mathrm{TiO}_{2}, \mathrm{ZnO}, \mathrm{Al}_{2} \mathrm{O}_{3}, \mathrm{Fe}_{2} \mathrm{O}_{3}$ \\
\hline & Zeng et al. (2017) [98] & Fresh, short-term aged, long-term aged & Graphene oxide \\
\hline & Ali et al. (2017) [93] & Fresh & $\mathrm{Al}_{2} \mathrm{O}_{3}$ \\
\hline & Sun et al. (2017) [67] & Fresh, asphalt mixture & $\mathrm{SiO}_{2}, \mathrm{TiO}_{2}, \mathrm{CaCO}_{3}, \mathrm{ZnO}$, montmorillonite, bentonite, $\mathrm{Fe}_{2} \mathrm{O}_{3}$ \\
\hline & Sadeghnejad et al. (2017) [51] & Fresh & $\mathrm{SiO}_{2}, \mathrm{TiO}_{2}$ \\
\hline & Hussein et al. (2017) [59] & Fresh & Ceramic powders \\
\hline & Li et al. (2018) [92] & Fresh, SBS modified & Graphene oxide \\
\hline & Zghair et al. (2020) [48] & Fresh & $\mathrm{SiO}_{2}$ \\
\hline & Sedaghat et al. (2020) [61] & Fresh, short-term aged, long-term aged & Clay (montmorillonite) \\
\hline ITF & Arabani et al. (2015) [83] & HMA & Carbon nanotubes \\
\hline Compatibility test & Li et al. (2015) [64] & Fresh, short-term aged, UV aged & $\mathrm{ZnO}$ \\
\hline TCLP & Hussein et al. (2017) [59] & Fresh & Ceramic powders \\
\hline Static creep test & Nejad et al. (2016) [95] & Fresh, HMA & $\mathrm{TiO}_{2}, \mathrm{ZnO}, \mathrm{Al}_{2} \mathrm{O}_{3}, \mathrm{Fe}_{2} \mathrm{O}_{3}$ \\
\hline MSCR & Liu et al. (2018) [94] & Fresh, HMA, WMA & Graphene oxide \\
\hline
\end{tabular}


Table 3. Cont.

\begin{tabular}{|c|c|c|c|}
\hline Techniques & Authors & Bitumen Matrix & Nano-Materials \\
\hline \multirow{2}{*}{ Direct tension test } & Karnati et al. (2019) [62] & Fresh, long-term aged & $\mathrm{SiO}_{2}$ \\
\hline & Karnati et al. (2020) [63] & Fresh, aged & $\mathrm{SiO}_{2}$ \\
\hline Thermal conductivity & Moreno-Navarro et al. (2018) [78] & Fresh & Graphene \\
\hline X-ray Photoelectron Spectroscopy (XPS) & Moreno-Navarro et al. (2018) [78] & Fresh & Graphene \\
\hline Optical microscopy & Moreno-Navarro et al. (2018) [78] & Fresh & Graphene \\
\hline Softening point test & Moreno-Navarro et al. (2018) [78] & Fresh & Graphene \\
\hline \multirow{2}{*}{ Wheel tracking } & Galooyak et al. (2015) [49] & Fresh, WMA & $\mathrm{SiO}_{2}$ \\
\hline & Crucho et al. (2018) [50] & Fresh, asphalt mixture & $\mathrm{SiO}_{2}$, zero-valent iron, clay \\
\hline Flow test & Ghasemi et al. (2012) [47] & Fresh, HMA & $\mathrm{SiO}_{2}$ \\
\hline Marshall stability & Ghasemi et al. (2012) [47] & Fresh, HMA & $\mathrm{SiO}_{2}$ \\
\hline Affinity test & Crucho et al. (2018) [50] & Fresh, asphalt mixture & $\mathrm{SiO}_{2}$, zero-valent iron, clay \\
\hline Stiffness test & Crucho et al. (2018) [50] & Fresh, asphalt mixture & $\mathrm{SiO}_{2}$, zero-valent iron, clay \\
\hline Fatigue test & Crucho et al. (2018) [50] & Fresh, asphalt mixture & $\mathrm{SiO}_{2}$, zero-valent iron, clay \\
\hline
\end{tabular}




\section{A Critical Discussion on the Techniques of Characterization}

Generally, the most common techniques described in literature that are used to study bitumen modification involves rheology measurements [100,101]. However, recently, more sophisticated techniques are also being used. Among these, nuclear magnetic resonance techniques have proven to be able to give detailed information both from the structural and from the dynamical point of views [102-105].

Another important technique is the X-ray scattering/diffraction. This can probe the structure at the nanoscale in soft and hard condensed matter.

In particular, small-angle X-ray scattering (SAXS), ultra-small angle x-rays scattering (USAXS) and wide-angle $x$-rays scattering (WAXS) are among the most employed experimental techniques for the investigation, in non-invasive way, of the structural properties of materials and complex self-assembly processes in a large variety of environments [106].

This non-destructive method efficiently evidences the formation of different nanostructures and morphologies thus highlighting the important role of the relevant molecular conformations in many different processes in the field on nanomaterials science [106].

More specifically the employment of synchrotron-based (multi-scale) X-ray scattering techniques allows advanced characterization of nano-structural properties and structural time evolution in large variety of materials systems including polymeric systems [107-112] organic structures including bio-materials and bio-(macro)molecules, [112-116] zeolites [117-119], alloys, ceramics and composite materials $[119,120]$.

Their enormous potentialities and how they can be successfully applied to bitumens and asphalts, have been already discussed in some recent papers [121,122].

However, the reader may surely agree with us that the synergistic use of different techniques can give an even better comprehension of the complex physico-chemistry involved in these materials [123].

Due to the complexity of nanoparticles-containing bitumens and asphalts, it is clear that different techniques can probe different things, giving therefore different information. Due to the same complexity of the material under study, different questions now arise. Let's address each of them in the following subsections.

\subsection{How to Probe the Presence of Nanoparticles by FT-IR}

We have shown how functionalization of inorganic nanoparticles is an emerging way to improve nanoparticle dispersion within the bituminous matrix. Such expensive methods require a technique to easily, and possibly cheaply, observe if the surface functionalization has taken place and to what extent.

Usually FT-IR has been used for this purpose. For example, the antioxidant effect of the two inorganic nanoparticles was deepened by FTIR by Nazari et al. [55]. However, also Hussein et al. [59], Li et al. [64], Karnati et al. [62] cited in the present work, have used FT-IR spectroscopy, as it can be seen by perusal of Table 3, which gives a panoramic view of the techniques used for investigating the properties of nanoparticles containing bitumens and asphalts.

Some comments are now due. Taking the work by Ali et al. [93] as a representative example, the authors, suspecting an irregular dispersion of the nanoparticles in binder, carried out a FT-IR investigation. In their work, the IR peak shifts were individuated as indicators of the coupling agent binding to the nanoparticle surface. We reproduce their key figure in Figure 5

In their work, tiny shifts of the peaks were interpreted as the consequence that asphalt is subjected to no obvious changes during modification. This was interpreted as that modification of asphalt with $\mathrm{Al}_{2} \mathrm{O}_{3}$ nanoparticles is merely a physical process.

We want to take inspiration from this conclusion to warn that in infra-red spectroscopy even small shifts in the absorption peaks can reveal interesting changes in the vibrational states of the functional groups. This can actually unveil real changes in interactions, which can be effectively treated through proper analysis [124]. An effective analysis must pass, in our opinion, through the separate analysis of the various IR ranges in which the functional groups absorb [125]. 


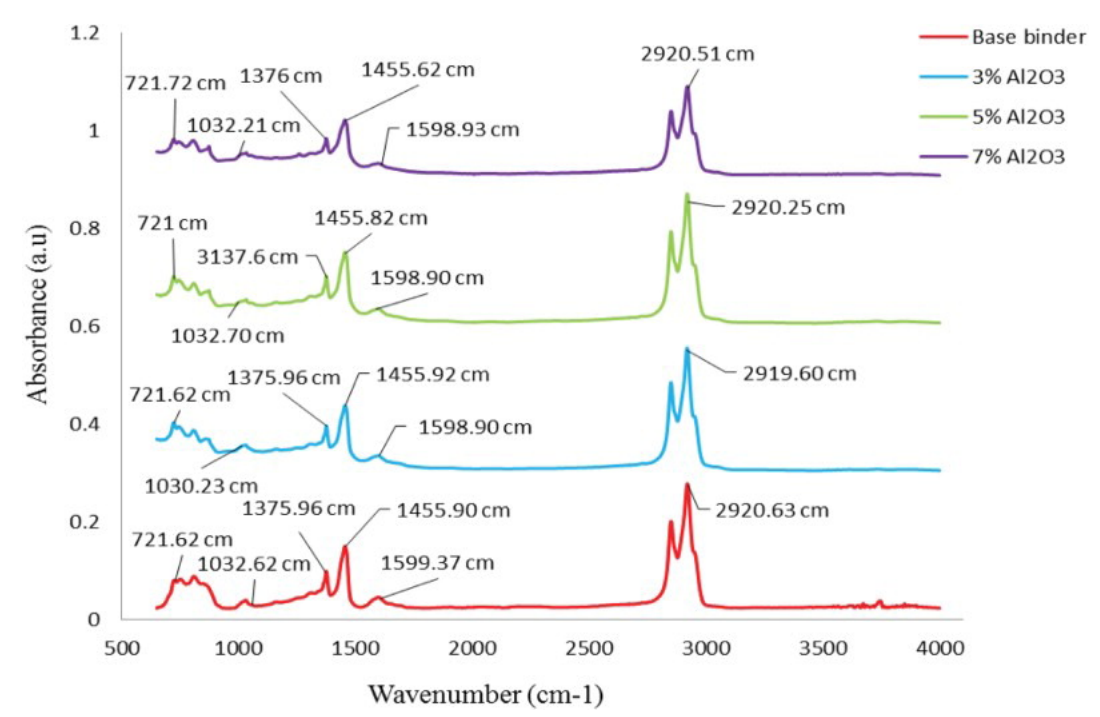

Figure 5. Spectra of the neat and $\mathrm{Al}_{2} \mathrm{O}_{3}$-modified bitumens studied by Ali et al. [93].

For example, it has been seen that the frequency of $\mathrm{C}-\mathrm{H}$ stretching are usually quite robust but the relative intensities of the $\mathrm{CH}_{2}$ and $\mathrm{CH}_{3}$ symmetric and antisymmetric contributions are not, so they are usually indicated as interesting indicators of the chain packing $[11,126]$.

\subsection{How to Probe the Distribution of Nanoparticles: Nanotomography as One of the Techniques of Election}

If nanoparticle-containing bitumens are studied, a specific aspect must be faced: the spatial distribution and organization of the nanoparticles within the bituminous matrix. It is obvious, in fact, that the nanoparticle distribution is of pivotal importance in the final properties.

From the structural point of view, being asphalt concretes heterogeneous materials, composed of aggregates, bitumen and porous networks, their mechanical properties depend on many factors such as the form and the distribution of the aggregate, the asphalt content, the pore content, pore distribution, and so on.

To face this problem, usually researchers probe the dispersion of nanoparticles within the bitumen or asphalts by microscopies, essentially scanning electron microscopy (SEM). Table 3 reports as summary of the techniques used by various authors, from which those who used SEM can be easily extracted.

As a representative example only, Taherkhani and Afroozi [99] in 2016 used SEM to probe the dispersion of the nanoparticles in the binder. Although they were able to find some nanoparticle tendency in aggregation and their tendency to form a network of aggregates responsible for the mechanical properties of the modified binder, it must be said that SEM is a surface method and it is not fit for probing the inner part of the material.

The problem is therefore twofold:

(1) On the one hand side, the technique must be able to probe the nanoparticles, differentiating their signal from that of the rest of the material.

(2) On the other hand, the technique must be able to also probe the inner part of the sample.

None of the above cited techniques can solve these two problems simultaneously.

For this reason, we want to point out the emergence of an interesting method for nanoparticles-containing matrices: nanotomography. It is a non-destructive technique which-like its related modalities tomography and microtomography-uses $\mathrm{x}$-rays to create cross-sections from a 3D-object that later can be used to recreate a virtual model. However, unlike the classical tomography in the nano case the pixel sizes of the cross-sections are in the nanometer range. More common applications of micro- and nano-tomography can be found in many areas of research and development like: materials science, geology, biomedical engineering, dentistry, bio-engineering, building engineering. In all 
these fields, the X-ray computed tomography (XCT) deals with materials of which the fine internal structure or the changes within the material are of outmost importance to understand the behavior of the material or to have insights in the processes going on. The interested reader can find more information in [127]. In the field of bitumen nanotomography technique was used by different authors to analyze and reconstruct the 3D structure of bitumen modified with different nanomaterials.

For example, nano-computed tomography (n-CT) was used to investigate the distribution of montmorillonite nanoparticles in the asphalt system [128]. Figure 6 shows the 3D distribution image of sodium montmorillonite nanoparticles in the bitumen at the maximum resolution (about $1 \mu \mathrm{m}$ ) of the CT scanning equipment as obtained by those authors.

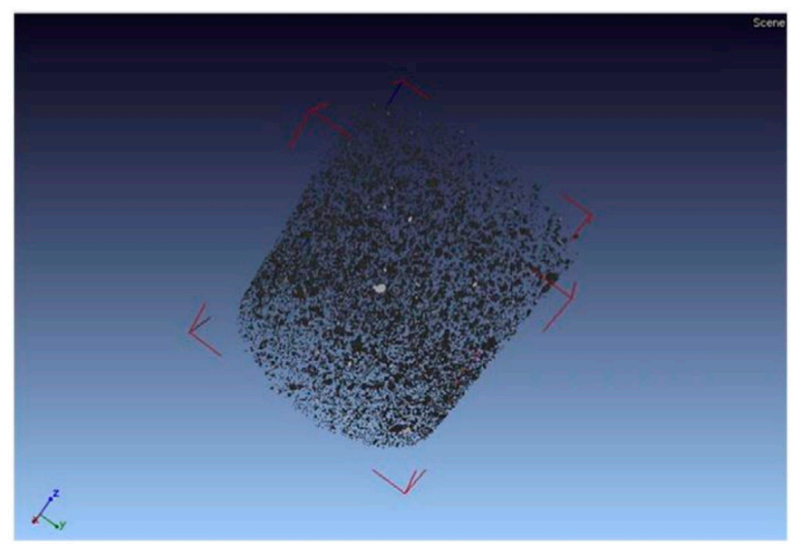

Figure 6. 3D distribution image of $\mathrm{Na}^{+}$montmorillonite particles in the bitumen.

Mohajeri et al. used the XCT technique visualize the interface between bitumen binder present in a reclaimed asphalt pavement (RAP) and a virgin bitumen used to blend it for new pavement surfacing [129]. XCT can also study the voids or to know the exact distribution of certain compounds to understand their effective layer-to-layer distribution inside the asphalt concrete as depicted in Figure 7 [130].

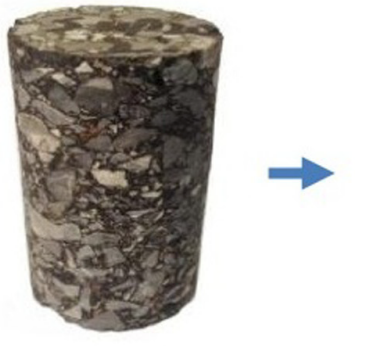

(a)

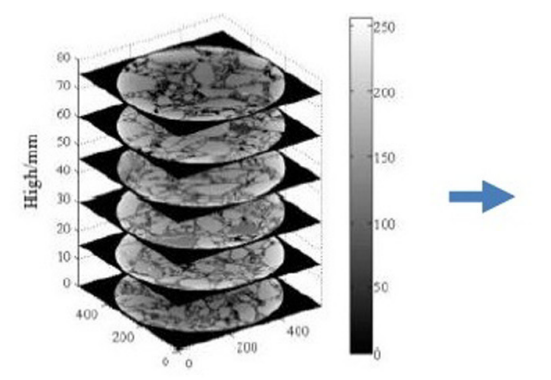

(b)

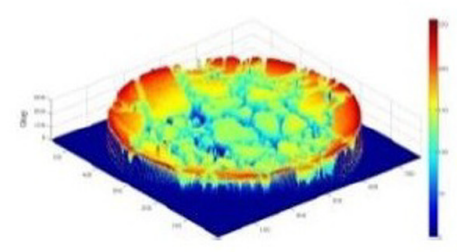

(c)

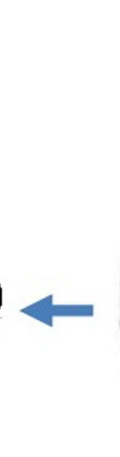

(e)

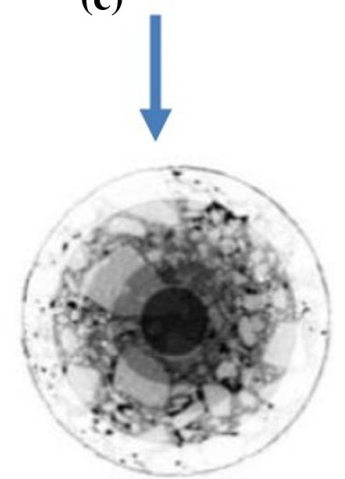

(d)

Figure 7. Extraction of the area of interest using CT scan technology [130]. (a) Asphalt concrete, (b) tomographic images, (c) gray distribution, (d) are of interest divided by annular masks, (e) initial binary image, (f) aggregate particles (>2.36 mm), (g) air-voids. 
Another example of the successful application of the CT scan can be found in [131], where the authors used small quantities of $\mathrm{TiO}_{2}$ as tracing agents of the virgin bitumen. In this way the blending between a virgin bitumen and a reclaimed asphalt pavement (RAP) could be studied.

Figure 8 shows 3D images of the cylinder-like sample of an asphalt concrete, in which the spatial distribution of the large virgin (shown in red, characterized by the presence of the tracing nanoparticles) and small RAP aggregates (shown in green) are evidenced inside the sample.
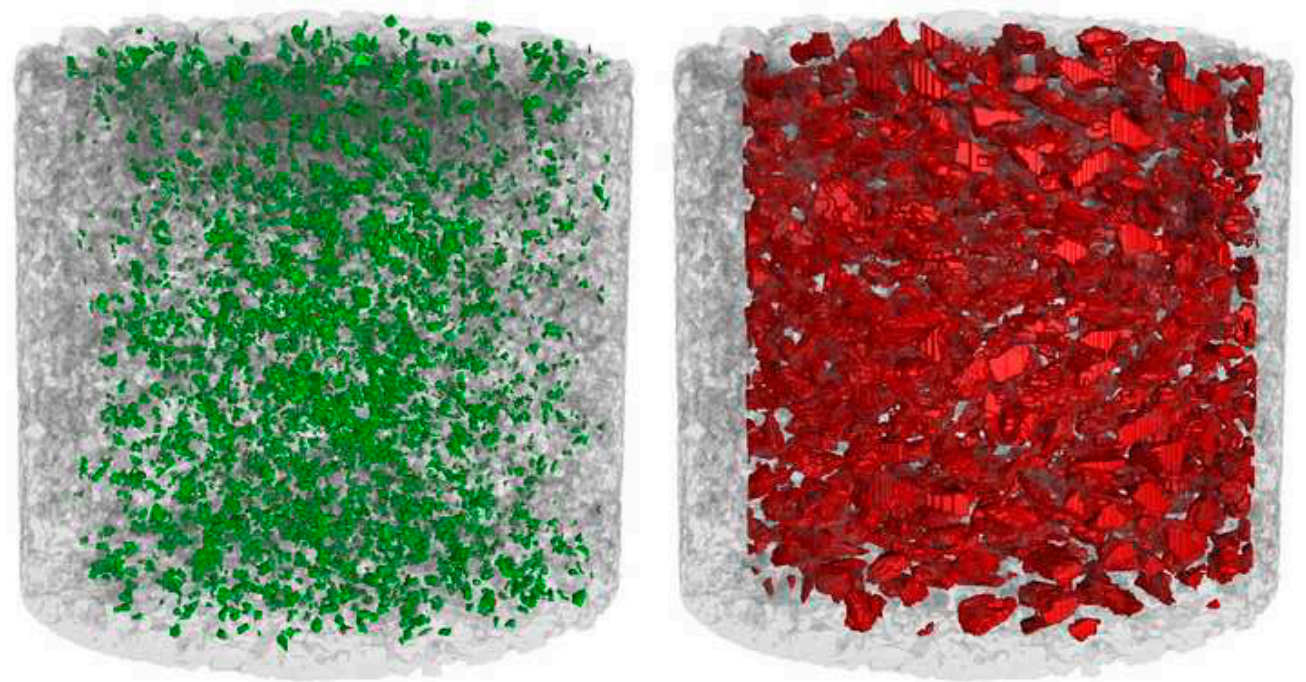

Figure 8. 3D images of the whole cylinder, as discussed in the text. The spatial distribution inside the sample of the large virgin and small RAP aggregates is shown with different colors (red and green, respectively).

\subsection{UV-Vis Absorption for Probing Bitumen Screening towards UV Radiation}

Some nanoparticles, due to their semiconductor nature, can absorb radiations whose energies are above the semiconductor energy gap. This energy threshold of absorption can be changed by changing the type of nanoparticles: for example, as expected, the widely-used nano- $\mathrm{SiO}_{2}$ cannot counteract the effect of photo-oxidation due to UV aging [66] since its energy gap is too high $(7.5-9.6 \mathrm{eV}[132,133])$. It is, indeed, considered more as an insulator rather than a semiconductor.

The energy threshold of absorption can also be changed by changing nanoparticle size and the efficiency of absorption by the inner structure governing the physical nature (direct or indirect) of the photon absorption [134]. This actually provides researchers with a further method to tune the absorption of radiation. For this reason, the capability of nanoparticles to absorb photons must be exactly determined for a wise design of a performing bitumen, and this requires suitable techniques for nanoparticle characterization.

This aspect can be in-depth explored by a simple UV-Vis spectroscopy technique, which can probe the photophysical behaviour through very simple data analysis, allowing the determination of both the energy gap and the efficiency of absorption. [26,135].

The possibility to tune the probability of photon absorption by changing the nanoparticle structural characteristics could be, in our opinion, a powerful way to further enhance the resistance of a nanoparticle-modified bitumen to the photo-induced ageing, which deserves much attention. For examples, the presence in traces of a metal within nanoparticles can induce a lowering of the nanoparticle energy gap (sensitization) thus extending the wavelength range of the photons which are absorbed. [26,135]. More absorbed photons means that the resulting nanoparticle-containing bitumen can be more resistant to photo-induced ageing. Here the same consideration on costs holds: it is obvious that obtaining nanoparticles with enhanced photophysical properties involves huge costs, but progresses in specialized technologies for their productions and an eventual increasing market can 
make, with time, the use of such kind of nanoparticles affordable, with unprecedented benefits, in our opinion, in terms of durability of bituminous materials.

\section{Conclusions and Perspectives}

Nanoparticles have unique properties. Recent progress in nanotechnology has allowed their preparation and modification with control even at the atomic level. Two approaches for nanoparticle production can be followed: they are top-down and bottom up. The former starts from bulk materials to obtain nano-sized particles through mainly physical processes. Ball milling is, for example, a cheap and quick such method. On the other hand, bottom-up approaches obtain nanoparticles from atomic and molecular precursors by self-assembly. The use of nanoparticles in bitumens must be scalable and cheap, so the former are preferred.

Recent works show that the nanoparticle surface has a pivotal importance in their embedding into the bitumen matrix. In this context we want to point out that the specific surface can be greatly enhanced if zeolites are used: modern protocols [136] individuate different stages in their growth so different morphologies can be obtained. In addition, surface manipulation allows the functionalization of certain nanoparticles with clear benefits in terms of increased affinity towards the bitumen apolar nature. The proper engineering of the bitumen addition with nanoparticles implies higher costs, obviously, but on the other hand it is clear that presence of nanoparticles can greatly enhance the mechanical properties of bitumens, potentially conferring also other new/novel important properties. Among these, the resistance to UV radiation is the most appealing to our eyes, granting higher stability over long times. Exploiting this possibility requires skills in photophysics, which widens the competencies required for research in this field and clearly indicating that multidisciplinarity is necessary. In any case, all this can be studied within the framework of the physics of complex systems, where the simultaneous presence of different chemical ingredients can give sometimes unexpected, but advanced, characteristics thanks to synergistic/cooperative effects among them, which are worth tailoring for specific applications [137].

All this has a cost, not only economic but also in the general sense of resources (time, availability of instruments, know-how ... ). Apart from some brilliant solutions to reuse nanoparticles from wastes, like that of Hussein et al. [59], which is a strategy we strongly support for environmental concerns and for sustainable economy, at the moment the costs are generally high and affect negatively the affordability of nanoparticle use in bitumens and asphalt addition, but in our opinion, the high costs are due to the fact that the use of nanoparticles in bitumens is still quite recent, so we are confident that with the development of technology the costs will lower and demand will increase. We believe that the discoveries in nanotechnology field, which have been always confined to small-quantities applications, can also be beneficial in large-scale applications like road pavement, in the next future. This is probably the biggest challenge in modern technology but we hope that it will be achieved soon in the field of bitumen, since the intelligent incorporation of nanoparticles can give, as it has been shown, novel properties of extreme added-value.

Author Contributions: Writing-Original Draft Preparation, P.C. (Pietro Calandra) and V.L.; Writing—Review \& Editing, P.C. (Pietro Calandra); Conceptualization, M.P. and D.L.; Investigation, V.L. and M.P.; Conceptualization and Supervision, P.C. (Paolino Caputo) and C.O.R. All authors have read and agreed to the published version of the manuscript.

Funding: This research received no external funding.

Conflicts of Interest: The author declares no conflict of interest.

\section{References}

1. Petrauskas, D.; Saleem, U. The Shell bitumen handbook. In The Shell Bitumen Handbook; Read, J., Whiteoak, D., Eds.; Thomas Telford: London, UK, 2003; p. 29. ISBN 072773220X. 
2. Paliukaitè, M.; Vaitkus, A.; Zofka, A. Evaluation of bitumen fractional composition depending on the crude oil type and production technology. In Proceedings of the 9th International Conference on Environmental Engineering, Vilnius, Lithuania, 22-24 May 2014.

3. Porto, M.; Caputo, P.; Loise, V.; Eskandarsefat, S.; Teltayev, B.; Rossi, C.O. Bitumen and bitumen modification: A review on latest advances. Appl. Sci. 2019, 9, 742. [CrossRef]

4. EN 12597 Bitumen and Bituminous Binders-Terminology; European Commetee for Standardization: Brussels, Belgium, 2000.

5. Yoon, S.; Bhatt, S.D.; Lee, W.; Lee, H.Y.; Jeong, S.Y.; Baeg, J.-O.; Lee, C.W. Separation and characterization of bitumen from Athabasca oil sand. Korean J. Chem. Eng. 2009, 26, 64-71. [CrossRef]

6. Lesueur, D. The colloidal structure of bitumen: Consequences on the rheology and on the mechanisms of bitumen modification. Adv. Colloid Interface Sci. 2009, 145, 42-82. [CrossRef] [PubMed]

7. Calandra, P.; Caputo, P.; De Santo, M.P.; Todaro, L.; Turco Liveri, V.; Oliviero Rossi, C. Effect of additives on the structural organization of asphaltene aggregates in bitumen. Constr. Build. Mater. 2019, 199, $288-297$. [CrossRef]

8. Loise, V.; Caputo, P.; Porto, M.; Calandra, P.; Angelico, R.; Rossi, C.O. A review on Bitumen Rejuvenation: Mechanisms, materials, methods and perspectives. Appl. Sci. 2019, 9, 4316. [CrossRef]

9. Hunter, R.; Self, A.; Read, J. The Shell Bitumen Handbook, 6th ed.; Hunter, R., Ed.; ICE Publishing: London, UK, 2015; ISBN 0727758373.

10. Firoozifar, S.H.; Foroutan, S.; Foroutan, S. The effect of asphaltene on thermal properties of bitumen. Chem. Eng. Res. Des. 2011, 89, 2044-2048. [CrossRef]

11. Calandra, P.; Ruggirello, A.; Mele, A.; Liveri, V.T. Self-assembly in surfactant-based liquid mixtures: Bis(2-ethylhexyl)phosphoric acid/bis(2-ethylhexyl)amine systems. J. Colloid Interface Sci. 2010, 348, 183-188. [CrossRef]

12. Calandra, P.; Turco Liveri, V.; Riello, P.; Freris, I.; Mandanici, A. Self-assembly in surfactant-based liquid mixtures: Octanoic acid/Bis(2-ethylhexyl)amine systems. J. Colloid Interface Sci. 2012, 367, 280-285. [CrossRef]

13. Calandra, P.; Mandanici, A.; Liveri, V.T. Self-assembly in surfactant-based mixtures driven by acid-base reactions: Bis(2-ethylhexyl) phosphoric acid-n-octylamine systems. RSC Adv. 2013, 3, 5148-5155. [CrossRef]

14. Calandra, P.; Mandanici, A.; Turco Liveri, V.; Pochylski, M.; Aliotta, F. Emerging dynamics in surfactant-based liquid mixtures: Octanoic acid/bis(2-ethylhexyl) amine systems. J. Chem. Phys. 2012, 136, 064515. [CrossRef]

15. Calandra, P.; Nicotera, I.; Rossi, C.O.; Liveri, V.T. Dynamical properties of self-assembled surfactant-based mixtures: Triggering of one-dimensional anomalous diffusion in bis(2-ethylhexyl)phosphoric acid/n-octylamine systems. Langmuir 2013, 29, 14848-14854. [CrossRef] [PubMed]

16. Lombardo, D.; Calandra, P.; Pasqua, L.; Magazù, S. Self-assembly of Organic Nanomaterials and Biomaterials: The Bottom-Up Approach for Functional Nanostructures Formation and Advanced Applications. Materials 2020, 13, 1048. [CrossRef] [PubMed]

17. Oliviero Rossi, C.; Ashimova, S.; Calandra, P.; De Santo, M.P.; Ruggero, A. Mechanical resilience of modified bitumen at different cooling rates: A rheological and atomic force microscopy investigation. Appl. Sci. 2017, 7, 779. [CrossRef]

18. Calandra, P.; Longo, A.; Ruggirello, A.; Turco Liveri, V. Physico-Chemical Investigation of the State of Cyanamide Confined in AOT and Lecithin Reversed Micelles. J. Phys. Chem. B 2004, 108, 8260-8268. [CrossRef]

19. Calandra, P.; Giordano, C.; Ruggirello, A.; Turco Liveri, V. Physicochemical investigation of acrylamide solubilization in sodium bis(2-ethylhexyl)sulfosuccinate and lecithin reversed micelles. J. Colloid Interface Sci. 2004, 277, 206-214. [CrossRef]

20. Calandra, P.; Marco, G.D.; Ruggirello, A.; Liveri, V.T. Physico-chemical investigation of nanostructures in liquid phases: Nickel chloride ionic clusters confined in sodium bis(2-ethylhexyl) sulfosuccinate reverse micelles. J. Colloid Interface Sci. 2009, 336, 176-182. [CrossRef]

21. Longo, A.; Banerjee, D.; Hermida-Merino, D.; Portale, G.; Calandra, P.; Turco Liveri, V. Induced Chirality in Confined Space on Halogen Gold Complexes. J. Phys. Chem. C 2015, 119, 18798-18807. [CrossRef]

22. Longo, A.; Calandra, P.; Casaletto, M.P.; Giordano, C.; Venezia, A.M.; Liveri, V.T. Synthesis and physico-chemical characterization of gold nanoparticles softly coated by AOT. Mater. Chem. Phys. 2006, 96, 66-72. [CrossRef] 
23. Calandra, P.; Giordano, C.; Longo, A.; Liveri, V.T. Physicochemical investigation of surfactant-coated gold nanoparticles synthesized in the confined space of dry reversed micelles. Mater. Chem. Phys. 2006, 98, 494-499. [CrossRef]

24. Calandra, P. Synthesis of Ni nanoparticles by reduction of $\mathrm{NiCl} 2$ ionic clusters in the confined space of AOT reversed micelles. Mater. Lett. 2009, 63, 2416-2418. [CrossRef]

25. Calandra, P.; Lombardo, D.; Neri, F.; Ruggirello, A.; Trusso, S.; Liveri, V.T. Synthesis of Yb nanoparticles by laser ablation of ytterbium target in sodium bis(2-ethylhexyl)sulfosuccinate reverse micellar solution. Mater. Lett. 2010, 64, 576-579. [CrossRef]

26. Calandra, P.; Lombardo, D.; Pistone, A.; Liveri, V.; Trusso, S. Structural and optical properties of novel surfactant-coated Yb@TiO2 nanoparticles. J. Nanopart. Res. 2011, 13, 5833-5839. [CrossRef]

27. Apostolidis, P.; Liu, X.; Kasbergen, C.; Scarpas, A.T. Synthesis of asphalt binder aging and the state of the art of antiaging technologies. Transp. Res. Rec. 2017, 2633, 147-153. [CrossRef]

28. European Commission. European Commission Recommendation of 18 October 2011 on the definition of nanomaterial, 2011/696/EU. Off. J. Eur. Union 2011, 275, 38-40.

29. Steyn, W. Applications of Nanotechnology in Road Pavement Engineering. In Nanotechnology in Civil Infrastructure-A Paradigm Shift; Springer: Berlin/Heidelberg, Germany, 2011; pp. 49-84. ISBN 978-3-642-16656-3.

30. Donegà, C. The Nanoscience Paradigm: “Size Matters!". In Nanoparticles: Workhorses of Nanoscience; Donega, C.d.M., Ed.; Springer: Berlin/Heidelberg, Germany, 2014; pp. 1-12.

31. Malsch, I. Nanotechnology in Europe: Scientific trends and organizational dynamics. Nanotechnology 1999, 10, 1-7. [CrossRef]

32. Zhu, W.; Bartos, P.; Porro, A. Application of nanotechnology in construction. Mater. Struct. 2004, 37, 649-658. [CrossRef]

33. Roduner, E. Nanoscopic Materials Size-Dependent Phenomena, 1st ed.; RSC: Cambridge, UK, 2006; ISBN 10: 085404857X.

34. Pacheco-Torgal, F.; Jalali, S. Nanotechnology: Advantages and drawbacks in the field of construction and building materials. Constr. Build. Mater. 2011, 25, 582-590. [CrossRef]

35. Sobolev, K.; Gutierrez, M.F. How Nanotechnology Can Change The Concrete World Part 1. Am. Ceram. Soc. Bull. 2005, 84, 14-17.

36. Correia, A. PHANTOMS: Nanotechnology network for information processing and storage. Nanotechnology 2001, 12, 89-90. [CrossRef]

37. Sohnel, O.; Garside, J. Precipitation: Basic Principles and Industrial Applications; Butterworth-Heinemann: Oxford, UK, 1992; ISBN 0750611073.

38. Ludwig, F.P.; Schmelzer, J. Cluster Formation and Growth in Segregation Processes with Constant Rates of Supply of Monomers. Z. Phys. Chem. 1995, 192, 155-167. [CrossRef]

39. Karahancer, S.; Saltan, M.; Morova, N.; Serin, S.; Terzi, S. Evaluation of rice husk ash as filler in hot mix asphalt concrete. Constr. Build. Mater. 2013, 48, 390-397.

40. Martinho, F.; Picado-Santos, L.; Capitão, S. Feasibility Assessment of the Use of Recycled Aggregates for Asphalt Mixtures. Sustainability 2018, 10, 1737. [CrossRef]

41. Filonzi, A.; Sabaraya, I.V.; Hajj, R.; Das, D.; Saleh, N.B.; Bhasin, A. Evaluating the Use of Nanomaterials to Enhance Properties of Asphalt Binders and Mixtures; Technical report 0-6854-1; University of Texas-Center for Trasportation Research: Austin, TX, USA, 2017.

42. Crucho, J.; Picado-Santos, L.; Neves, J.; Capitão, S. A review of nanomaterials' effect on mechanical performance and aging of asphalt mixtures. Applied. Sci. 2019, 9, 3657. [CrossRef]

43. $\mathrm{Fe}_{2} \mathrm{O}_{3}$ Iron Oxide Nanoparticles/Nanopowder (Alpha, 99.9\%, 5nm, Red). Available online: https://www.usnano.com/inc/sdetail/50544 (accessed on 10 June 2020).

44. Singh, L.P.; Karade, S.R.; Bhattacharyya, S.K.; Yousuf, M.M.; Ahalawat, S. Beneficial role of nanosilica in cement based materials-A review. Constr. Build. Mater. 2013, 47, 1069-1077. [CrossRef]

45. Li, R.; Xiao, F.; Amirkhanian, S.; You, Z.; Huang, J. Developments of nano materials and technologies on asphalt materials-A review. Constr. Build. Mater. 2017, 143, 633-648. [CrossRef]

46. Yang, J.; Tighe, S. A Review of Advances of Nanotechnology in Asphalt Mixtures. Procedia-Soc. Behav. Sci. 2013, 96, 1269-1276. [CrossRef] 
47. Ghasemi, M.; Marandi, M.; Tahmooresi, M.; Jalal kamali, R.; Taherzade, R. Modification of Stone Matrix Asphalt with Nano-SiO 2 . J. Basic Appl. Sci. Res. 2012, 2, 1338-1344.

48. Zghair, H.H.; Jony, H.; Hassan, M. Rheological Characteristics of Nano Silica Modified Asphalt Binder Material. In Proceedings of the 2019 International Engineering Conference (IEC), Erbil, Iraqi Kurdistan, 23-24 April 2019; pp. 79-84.

49. Galooyak, S.S.; Palassi, M.; Goli, A.; Farahani, H.Z. Performance Evaluation of Nano-silica Modified Bitumen. Int. J. Transp. Eng. 2015, 3, 55-66.

50. Crucho, J.M.L.; das Neves, J.M.C.; Capitão, S.D.; de Picado-Santos, L.G. Mechanical performance of asphalt concrete modified with nanoparticles: Nanosilica, zero-valent iron and nanoclay. Constr. Build. Mater. 2018, 181, 309-318. [CrossRef]

51. Sadeghnejad, M.; Shafabakhsh, G. Experimental Study on the Physical and Rheological Properties of Bitumen Modified with Different Nano Materials (Nano $\mathrm{SiO}_{2} \& \mathrm{Nano}_{\mathrm{TiO}}$ ). Int. J. Nanosci. Nanotechnol. 2017, 13, 253-263.

52. Nejad, F.M.; Nazari, H.; Naderi, K.; Karimiyan Khosroshahi, F.; Hatefi Oskuei, M. Thermal and rheological properties of nanoparticle modified asphalt binder at low and intermediate temperature range. Pet. Sci. Technol. 2017, 35, 641-646. [CrossRef]

53. Shafabakhsh, G.H.; Sajadib, S.R. Evaluation of rheological behavior of bitumen modified with Nano Copper Oxide. Int. J. Eng. Technol. 2018, 7, 13-18. [CrossRef]

54. Amini, N.; Hayati, P. Effects of $\mathrm{CuO}$ nanoparticles as phase change material on chemical, thermal and mechanical properties of asphalt binder and mixture. Constr. Build. Mater. 2020, 251, 118996. [CrossRef]

55. Nazari, H.; Naderi, K.; Moghadas Nejad, F. Improving aging resistance and fatigue performance of asphalt binders using inorganic nanoparticles. Constr. Build. Mater. 2018, 170, 591-602. [CrossRef]

56. Uddin, F. Clays, Nanoclays, and Montmorillonite Minerals. Metall. Mater. Trans. A 2008, 39, $2804-2814$. [CrossRef]

57. Phyllosilicates (Micas, Chlorite, Talc, \& Serpentine). Available online: Tulane.edu/ \{\}sanelson/eens211/ phyllosilicates.htm. (accessed on 10 June 2020).

58. Jahromi, S.G.; Khodaii, A. Effects of nanoclay on rheological properties of bitumen binder. Constr. Build. Mater. 2009, 23, 2894-2904. [CrossRef]

59. Hussein, A.A.; Jaya, R.P.; Abdul Hassan, N.; Yaacob, H.; Huseien, G.F.; Ibrahim, M.H.W. Performance of nanoceramic powder on the chemical and physical properties of bitumen. Constr. Build. Mater. 2017, 156, 496-505. [CrossRef]

60. Mubaraki, M.; Ali, S.I.A.; Ismail, A.; Yusoff, N.I.M. Rheological Evaluation of Asphalt Cements Modified with ASA Polymer and $\mathrm{Al}_{2} \mathrm{O}_{3}$ Nanoparticles. Procedia Eng. 2016, 143, 1276-1284. [CrossRef]

61. Sedaghat, B.; Taherrian, R.; Hosseini, S.A.; Mojtaba Mousavi, S. Rheological properties of bitumen containing nanoclay and organic warm-mix asphalt additives. Constr. Build. Mater. 2020, 243, 118092. [CrossRef]

62. Karnati, S.R.; Oldham, D.; Fini, E.H.; Zhang, L. Surface functionalization of silica nanoparticles to enhance aging resistance of asphalt binder. Constr. Build. Mater. 2019, 211, 1065-1072. [CrossRef]

63. Karnati, S.R.; Oldham, D.; Fini, E.H.; Zhang, L. Application of surface-modified silica nanoparticles with dual silane coupling agents in bitumen for performance enhancement. Constr. Build. Mater. 2020, 244, 118324. [CrossRef]

64. Li, R.; Pei, J.; Sun, C. Effect of nano-ZnO with modified surface on properties of bitumen. Constr. Build. Mater. 2015, 98, 656-661. [CrossRef]

65. Zhang, H.; Zhu, C.; Yu, J.; Shi, C.; Zhang, D. Influence of surface modification on physical and ultraviolet aging resistance of bitumen containing inorganic nanoparticles. Constr. Build. Mater. 2015, 98, 735-740. [CrossRef]

66. Chen, Z.; Zhang, H.; Zhu, C.; Zhao, B. Rheological examination of aging in bitumen with inorganic nanoparticles and organic expanded vermiculite. Constr. Build. Mater. 2015, 101, 884-891. [CrossRef]

67. Sun, L.; Xin, X.; Ren, J. Inorganic nanoparticle-modified asphalt with enhanced performance at high temperature. J. Mater. Civ. Eng. 2017, 29, 1-9. [CrossRef]

68. Zhang, H.B.; Zhang, H.L.; Ke, N.X.; Huang, J.H.; Zhu, C.Z. The effect of different nanomaterials on the long-term aging properties of bitumen. Pet. Sci. Technol. 2015, 33, 388-396. [CrossRef]

69. Han, T.-H.; Kim, H.; Kwon, S.-J.; Lee, T.-W. Graphene-based flexible electronic devices. Mater. Sci. Eng. R Rep. 2017, 118, 1-43. [CrossRef] 
70. Nguyen, T.P.; Nguyen, D.L.T.; Nguyen, V.H.; Le, T.H.; Vo, D.V.N.; Ly, Q.V.; Kim, S.Y.; Van Le, Q. Recent progress in carbon-based buffer layers for polymer solar cells. Polymers 2019, 11, 1858. [CrossRef]

71. Vajtai, R. (Ed.) Springer Handbook of Nanomaterials, 1st ed.; Springer: Berlin/Heidelberg, Germany, 2013; ISBN 978-3-642-20594-1.

72. Young, R.J.; Kinloch, I.A.; Gong, L.; Novoselov, K.S. The mechanics of graphene nanocomposites: A review. Compos. Sci. Technol. 2012, 72, 1459-1476. [CrossRef]

73. Le, J.-L.; Du, H.; Pang, S.D. Use of 2D Graphene Nanoplatelets (GNP) in cement composites for structural health evaluation. Compos. Part B Eng. 2014, 67, 555-563. [CrossRef]

74. Du, H.; Pang, S.D. Enhancement of barrier properties of cement mortar with graphene nanoplatelet. Cem. Concr. Res. 2015, 76, 10-19. [CrossRef]

75. Du, H.; Pang, S.D. Mechanical Response and Strain Sensing of Cement Composites Added with Graphene Nanoplatelet under Tension BT-Nanotechnology in Construction; Sobolev, K., Shah, S.P., Eds.; Springer International Publishing: Cham, Switzerland, 2015; pp. 377-382.

76. Palmeri, M.J.; Putz, K.W.; Ramanathan, T.; Brinson, L.C. Multi-scale reinforcement of CFRPs using carbon nanofibers. Compos. Sci. Technol. 2011, 71, 79-86. [CrossRef]

77. Lu, S.-N.; Xie, N.; Feng, L.-C.; Zhong, J. Applications of Nanostructured Carbon Materials in Constructions: The State of the Art. J. Nanomater. 2015, 2015, 807416. [CrossRef]

78. Moreno-Navarro, F.; Sol-Sánchez, M.; Gamiz, F.; Gámez, M. Mechanical and thermal properties of graphene modified asphalt binders. Constr. Build. Mater. 2018, 180, 265-274. [CrossRef]

79. Aravind, S.; Isac, A.J.; Aparajith, S. Construction of porous asphalt pavement using graphene. Int. J. Recent Trends Eng. Res. 2018, 4, 475-481.

80. Habib, N.; Ng, C.; Zoorob, S.; Lee, P. Use of Graphene Oxide as a Bitumen Modifier: An Innovative Process Optimization Study. Adv. Mater. Res. 2015, 1105, 365-369. [CrossRef]

81. Cataldi, P.; Athanassiou, A.; Bayer, I. Graphene Nanoplatelets-Based Advanced Materials and Recent Progress in Sustainable Applications. Appl. Sci. 2018, 8, 1438. [CrossRef]

82. Le, J.; Marasteanu, M.; Turos, M. Graphene Nanoplatelet (GNP) Reinforced Asphalt Mixtures: A Novel Multifunctional Pavement Material. IDEA Program Final Report NCHRP 173. 2016, pp. 1-28. Available online: http://onlinepubs.trb.org/onlinepubs/IDEA/FinalReports/Highway/NCHRP173_Final_Report.pdf (accessed on 28 July 2020).

83. Arabani, M.; Faramarzi, M. Characterization of CNTs-modified HMA's mechanical properties. Constr. Build. Mater. 2015, 83, 207-215. [CrossRef]

84. Loise, V.; Vuono, D.; Policicchio, A.; Teltayev, B.; Gnisci, A.; Messina, G.; Oliviero Rossi, C. The effect of multiwalled carbon nanotubes on the rheological behaviour of bitumen. Colloids Surf. A Physicochem. Eng. Asp. 2019, 566, 113-119. [CrossRef]

85. Khattak, M.J.; Khattab, A.; Rizvi, H.R.; Zhang, P. The impact of carbon nano-fiber modification on asphalt binder rheology. Constr. Build. Mater. 2012, 30, 257-264. [CrossRef]

86. Rizvi, H.R.; Khattak, M.J.; Madani, M.; Khattab, A. Piezoresistive response of conductive Hot Mix Asphalt mixtures modified with carbon nanofibers. Constr. Build. Mater. 2016, 106, 618-631. [CrossRef]

87. Wu, S.; Zhang, Y.; Wang, J. A novel potential flame-retarded bitumen nanoclay modified bitumen. Road Mater. Pavement Des. 2009, 10, 115-128. [CrossRef]

88. Hamedi, G.H.; Nejad, F.M.; Oveisi, K. Estimating the moisture damage of asphalt mixture modified with nano zinc oxide. Mater. Struct. 2016, 49, 1165-1174. [CrossRef]

89. Erkens, S.; Porot, L.; Glaser, R.; Glover, C.J. Aging of Bitumen and Asphalt Concrete: Comparing State of the Practice and Ongoing Developments in the United States and Europe. In Proceedings of the Transportation Research Board 95th Annual Meeting, Washington, DC, USA, 10-14 January 2016.

90. Olabemiwo, O.M.; Lateef, A.; Agunbiade, F.O.; Akanji, S.B.; Bakare, H.O. The effects on oxidative aging, physical and flow properties of Agbabu natural bitumen modified with silver nanoparticles. Heliyon 2020, 6 , e04164. [CrossRef] [PubMed]

91. Du, P.; Ke, N.; Zhang, H. Effect of Nano-zinc Oxide on the Morphology and Ultraviolet Aging Properties of Various Bitumens. Pet. Sci. Technol. 2015, 33, 1110-1117. [CrossRef]

92. Li, Y.; Wu, S.; Amirkhanian, S. Investigation of the graphene oxide and asphalt interaction and its effect on asphalt pavement performance. Constr. Build. Mater. 2018, 165, 572-584. [CrossRef] 
93. Ali, S.I.A.; Ismail, A.; Karim, M.R.; Yusoff, N.I.M.; Al-Mansob, R.A.; Aburkaba, E. Performance evaluation of Al 2 O 3 nanoparticle-modified asphalt binder. Road Mater. Pavement Des. 2017, 18, 1251-1268. [CrossRef]

94. Liu, K.; Zhang, K.; Wu, J.; Muhunthan, B.; Shi, X. Evaluation of mechanical performance and modification mechanism of asphalt modified with graphene oxide and warm mix additives. J. Clean. Prod. 2018, 193, 87-96. [CrossRef]

95. Nejad, F.M.; Tanzadeh, R.; Tanzadeh, J.; Hamedi, G.H. Investigating the effect of nanoparticles on the rutting behaviour of hot-mix asphalt. Int. J. Pavement Eng. 2016, 17, 353-362. [CrossRef]

96. Yang, Q.; Li, X.; Zhang, L.; Qian, Y.; Qi, Y.; Kouhestani, H.S.; Shi, X.; Gui, X.; Wang, D.; Zhong, J. Performance evaluation of bitumen with a homogeneous dispersion of carbon nanotubes. Carbon 2020, 158, 465-471. [CrossRef]

97. Brcic, H. Investigation of the Rheological Properties of Asphalt Binder Containing Graphene Nanoplatelets. Master's Thesis, Norwegian University of Science and Technology, Norway, Norway, 2016.

98. Zeng, W.; Wu, S.; Pang, L.; Sun, Y.; Chen, Z. The Utilization of Graphene Oxide in Traditional Construction Materials: Asphalt. Materials 2017, 10, 48. [CrossRef]

99. Taherkhani, H.; Afroozi, S. The properties of nanosilica-modified asphalt cement. Pet. Sci. Technol. 2016, 34, 1381-1386. [CrossRef]

100. Porto, M.; Caputo, P.; Loise, V.; De Filpo, G.; Rossi, C.O.; Calandra, P. Polysaccharides-reinforced bitumens: Specificities and universality of rheological behavior. Appl. Sci. 2019, 9, 5564. [CrossRef]

101. Caputo, P.; Porto, M.; Calandra, P.; De Santo, M.P.; Oliviero Rossi, C. Effect of epoxidized soybean oil on mechanical properties of bitumen and aged bitumen. Mol. Cryst. Liq. Cryst. 2018, 675, 68-74. [CrossRef]

102. Caputo, P.; Porto, M.; Loise, V.; Teltayev, B.; Rossi, C.O. Analysis of mechanical performance of bitumen modified with waste plastic and rubber (SBR) additives by rheology and PGSE NMR experiments. Eurasian Chem. J. 2019, 21, 235-239. [CrossRef]

103. Caputo, P.; Loise, V.; Ashimova, S.; Teltayev, B.; Vaiana, R.; Oliviero Rossi, C. Inverse Laplace Transform (ILT)NMR: A powerful tool to differentiate a real rejuvenator and a softener of aged bitumen. Colloids Surf. A Physicochem. Eng. Asp. 2019, 574, 154-161. [CrossRef]

104. Rossi, C.O.; Caputo, P.; Loise, V.; Ashimova, S.; Teltayev, B.; Sangiorgi, C. A new green rejuvenator: Evaluation of structural changes of aged and recycled bitumens by means of rheology and NMR. In RILEM 252-CMB-Symposium on Chemo Mechanical Characterization of Bituminous Materials; Springer: Cham, Switzerland, 2018; Volume 20, pp. 177-182.

105. Oliviero, C.; Caputo, P.; Ashimova, S.; Fabozzi, A.; D'Errico, G.; Angelico, R. Effects of Natural Antioxidant Agents on the Bitumen Aging Process: An EPR and Rheological Investigation. Appl. Sci. 2018, 8, 1405. [CrossRef]

106. Walenta, E. Small angle X-ray scattering. Von O. GLATTER und O. KRATKY. London: Academic Press Inc. Ltd. 1982. ISBN 0-12-286280-5. X, 515 Seiten, geb. £ 43,60; US \$ 81.00. Acta Polym. 1985, 36, 296. [CrossRef]

107. Chu, B.; Hsiao, B.S. Small-Angle X-ray Scattering of Polymers. Chem. Rev. 2001, 101, 1727-1762. [CrossRef]

108. Nozue, Y.; Shinohara, Y.; Amemiya, Y. Application of Microbeam Small- and Wide-angle X-ray Scattering to Polymeric Material Characterization. Polym. J. 2007, 39, 1221-1237. [CrossRef]

109. Calandra, P.; Turco Liveri, V.; Ruggirello, A.M.; Licciardi, M.; Lombardo, D.; Mandanici, A. Anti-Arrhenian behaviour of conductivity in octanoic acid-bis(2-ethylhexyl)amine systems: A physico-chemical study. J. Mater. Chem. C 2015, 3, 3198-3210. [CrossRef]

110. Lombardo, D.; Munaò, G.; Calandra, P.; Pasqua, L.; Caccamo, M.T. Evidence of pre-micellar aggregates in aqueous solution of amphiphilic PDMS-PEO block copolymer. Phys. Chem. Chem. Phys. 2019, 21, 11983-11991. [CrossRef] [PubMed]

111. Turco Liveri, V.; Lombardo, D.; Pochylski, M.; Calandra, P. Molecular association of small amphiphiles: Origin of ionic liquid properties in dibutyl phosphate/propylamine binary mixtures. J. Mol. Liq. 2018, 263, 274-281. [CrossRef]

112. Hyland, L.L.; Taraban, M.B.; Yu, Y.B. Using small-angle scattering techniques to understand mechanical properties of biopolymer-based biomaterials. Soft Matter 2013, 9, 10218-10228. [CrossRef]

113. Ochbaum, G.; Bitton, R. Using small-angle X-ray scattering (SAXS) to study the structure of self-assembling biomaterials. In Self-Assembling Biomaterials; Azevedo, H.S., Silva, R.M.P., Eds.; Woodhead Publishing Series in Biomaterials; Woodhead Publishing: Cambridge, UK, 2018; pp. 291-304. ISBN 978-0-08-102015-9. 
114. Kiselev, M.A.; Lombardo, D. Structural characterization in mixed lipid membrane systems by neutron and X-ray scattering. Biochim. Biophys. Acta-Gen. Subj. 2017, 1861, 3700-3717. [CrossRef]

115. Lombardo, D.; Calandra, P.; Magazù, S.; Wanderlingh, U.; Barreca, D.; Pasqua, L.; Kiselev, M.A. Soft nanoparticles charge expression within lipid membranes: The case of amino terminated dendrimers in bilayers vesicles. Colloids Surf. B Biointerfaces 2018, 170, 609-616. [CrossRef]

116. Lombardo, D.; Calandra, P.; Bellocco, E.; Laganà, G.; Barreca, D.; Magazù, S.; Wanderlingh, U.; Kiselev, M.A. Effect of anionic and cationic polyamidoamine (PAMAM) dendrimers on a model lipid membrane. Biochim. Biophys. Acta 2016, 1858, 2769-2777. [CrossRef]

117. de Moor, P.-P.E.A.; Beelen, T.P.M.; van Santen, R.A.; Tsuji, K.; Davis, M.E. SAXS and USAXS Investigation on Nanometer-Scaled Precursors in Organic-Mediated Zeolite Crystallization from Gelating Systems. Chem. Mater. 1999, 11, 36-43. [CrossRef]

118. Bonaccorsi, L.; Calandra, P.; Kiselev, M.A.; Amenitsch, H.; Proverbio, E.; Lombardo, D. Self-assembly in poly(dimethylsiloxane)-poly(ethylene oxide) block copolymer template directed synthesis of Linde type A zeolite. Langmuir 2013, 29, 7079-7086. [CrossRef]

119. Ingham, B. X-ray scattering characterisation of nanoparticles. Crystallogr. Rev. 2015, 21, 229-303. [CrossRef]

120. Fratzl, P. Small-angle scattering in materials science - a short review of applications in alloys, ceramics and composite materials. J. Appl. Crystallogr. 2003, 36, 397-404. [CrossRef]

121. Rossi, C.O.; Caputo, P.; De Luca, G.; Maiuolo, L.; Eskandarsefat, S.; Sangiorgi, C. 1H-NMR spectroscopy: A possible approach to advanced bitumen characterization for industrial and paving applications. Appl. Sci. 2018, 8, 229.

122. Calandra, P.; Liveri, V.T.; Caputo, P.; Teltayev, B.; Rossi, C.O. Wide Angle X-ray Scattering as a Technique of Choice to Probe Asphaltene Hierarchical Structures. J. Nanosci. Nanotechnol. 2020, 20, 4574-4579. [CrossRef]

123. Caputo, P.; Loise, V.; Crispini, A.; Sangiorgi, C.; Scarpelli, F.; Oliviero Rossi, C. The efficiency of bitumen rejuvenator investigated through Powder X-ray Diffraction (PXRD) analysis and T2-NMR spectroscopy. Colloids Surf. A Physicochem. Eng. Asp. 2019, 571, 50-54. [CrossRef]

124. Bartolotta, A.; Calandra, P. Indication of Local Phase Separation in Polyimide/Silica Hybrid Polymers. Macromol. Chem. Phys. 2010, 211, 1784-1792. [CrossRef]

125. Pochylski, M.; Oliviero, C.; Nicotera, I.; Liveri, V.; Calandra, P. Nano-demixing as a novel strategy for magnetic field responsive systems: The case of Dibutyl phosphate/bis(2-ethylhexyl) amine systems. RSC Adv. 2016, 6, 26696-26708. [CrossRef]

126. Calandra, P.; Caponetti, E.; Chillura Martino, D.; D'Angelo, P.; Minore, A.; Turco Liveri, V. FT-IR and dielectric study of water/AOT liquid crystals. J. Mol. Struct. 2000, 522, 165-178. [CrossRef]

127. Midgley, P.A.; Ward, E.P.W.; Hungría, A.B.; Thomas, J.M. Nanotomography in the chemical, biological and materials sciences. Chem. Soc. Rev. 2007, 36, 1477-1494. [CrossRef]

128. Liu, G.; Wu, S.; Ven, M.; Yu, J.; Molenaar, A. Influence of sodium and organo-montmorillonites on the properties of bitumen. Appl. Clay Sci. 2010, 49, 69-73. [CrossRef]

129. Mohajeri, M.; Molenaar, A.A.A.; Van de Ven, M.F.C. Experimental study into the fundamental understanding of blending between reclaimed asphalt binder and virgin bitumen using nanoindentation and nano-computed tomography. Road Mater. Pavement Des. 2014, 15, 372-384. [CrossRef]

130. Hu, J.; Qian, Z.; Wang, D.; Oeser, M. Influence of aggregate particles on mastic and air-voids in asphalt concrete. Constr. Build. Mater. 2015, 93,1-9. [CrossRef]

131. Rinaldini, E.; Schuetz, P.; Partl, M.; Tebaldi, G.; Poulikakos, L. Investigating the blending of reclaimed asphalt with virgin materials using rheology, electron microscopy and computer tomography. Compos. Part B Eng. 2014, 67, 579-587. [CrossRef]

132. Tan, G.-L.; Lemon, M.F.; French, R.H. Optical Properties and London Dispersion Forces of Amorphous Silica Determined by Vacuum Ultraviolet Spectroscopy and Spectroscopic Ellipsometry. J. Am. Ceram. Soc. 2003, 86, 1885-1892. [CrossRef]

133. Ravindra, N.M.; Narayan, J. Optical properties of amorphous silicon and silicon dioxide. J. Appl. Phys. 1986, 60, 1139-1146. [CrossRef]

134. Serpone, N.; Lawless, D.; Khairutdinov, R. Size Effects on the Photophysical Properties of Colloidal Anatase TiO2 Particles: Size Quantization versus Direct Transitions in This Indirect Semiconductor? J. Phys. Chem. 1995, 99, 16646-16654. [CrossRef] 
135. Calandra, P.; Ruggirello, A.; Pistone, A.; Turco Liveri, V. Structural and Optical Properties of Novel Surfactant Coated TiO2-Ag Based Nanoparticles. J. Clust. Sci. 2010, 21, 767-778. [CrossRef]

136. Bonaccorsi, L.; Calandra, P.; Amenitsch, H.; Proverbio, E.; Lombardo, D. Growth of fractal aggregates during template directed SAPO-34 zeolite formation. Microporous Mesoporous Mater. 2013, 167, 3-9. [CrossRef]

137. Calandra, P.; Caschera, D.; Liveri, V.T.; Lombardo, D. How self-assembly of amphiphilic molecules can generate complexity in the nanoscale. Colloids Surf. A Physicochem. Eng. Asp. 2015, 484, 164-183. [CrossRef]

(c) (

(C) 2020 by the authors. Licensee MDPI, Basel, Switzerland. This article is an open access article distributed under the terms and conditions of the Creative Commons Attribution (CC BY) license (http://creativecommons.org/licenses/by/4.0/). 